\title{
Investigation of Wall Function and Turbulence Model Performance within the Wind Code
}

\author{
Vance Dippold, III \\ NASA Glenn Research Center, Cleveland, OH 44135
}

\begin{abstract}
A series of computational analyses is performed using three geometries to assess the performance of wall functions and various turbulence models within the Wind flow solver. The study simulates incompressible flow over a flat plate, incompressible flow through an asymmetric diffuser with separation, and flow through a dual-stream subsonic nozzle. Mentor's SST and Chien's $K-\varepsilon$ turbulence models were used. The grids had initial spacings at the wall ranging from $y^{+}=1$ to $y^{+}=60$ to assess the performance of the wall functions. Both two-equation turbulence models were found to work well in the presence of a neutral or favorable pressure gradient; however the SST model clearly performed better when an adverse pressure gradient was present. As expected, Wind's wall functions were able to adequately predict gross flowfield features in attached flow, but performed poorly with separated flow.
\end{abstract}

\section{Nomenclature}

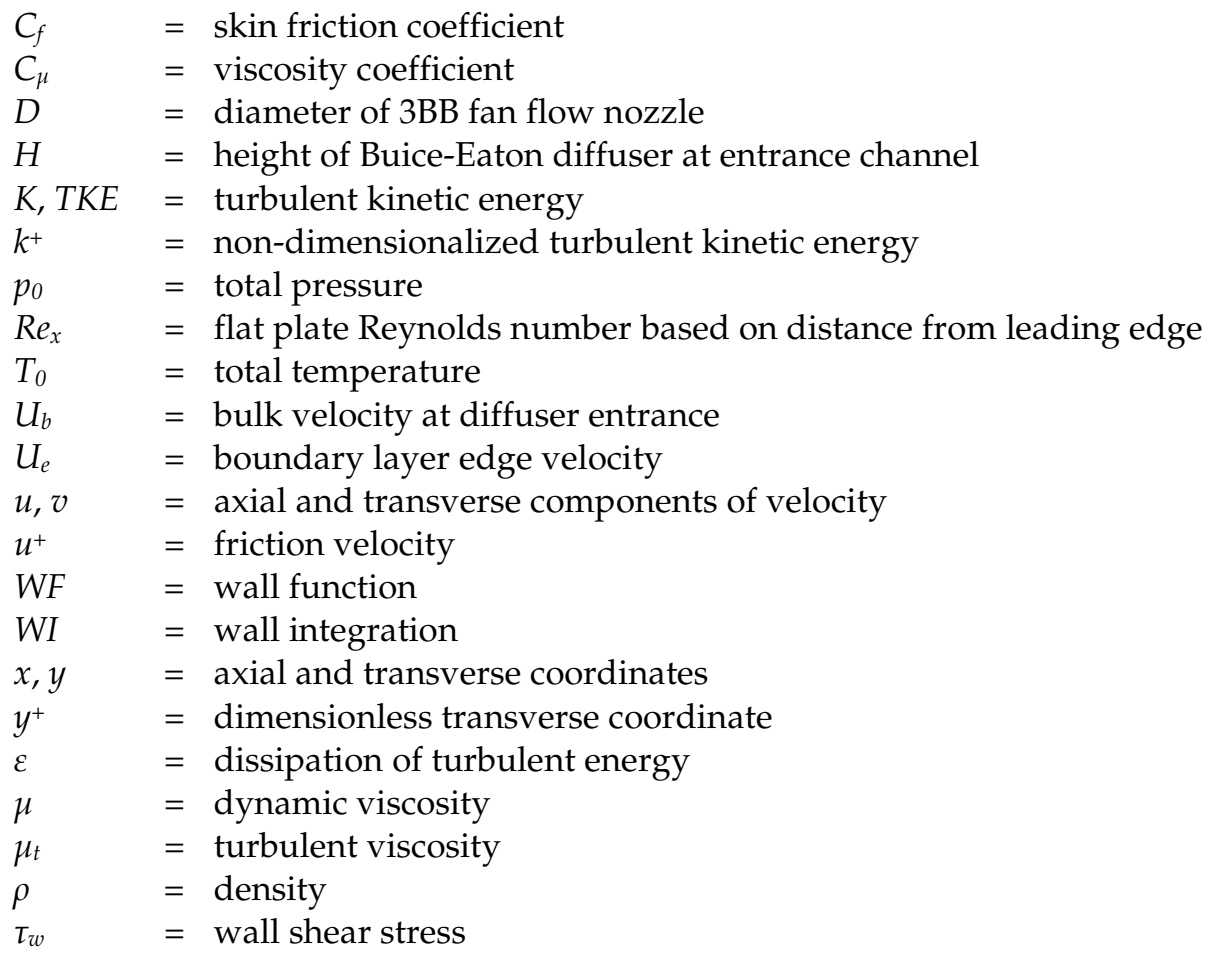

\section{Introduction}

The goal of this study is to observe the performance of wall functions and different turbulence models within the Wind ${ }^{1,2}$ computational fluid dynamics code. The Wind code uses the White-Christoph

\footnotetext{
*Aerospace Engineer, Nozzle Branch, 21000 Brookpark Rd, M.S. 86-7, Member AIAA
} 
law of the wall in its wall function calculations ${ }^{3,4}$. The Law of the wall assumes that, for attached flow without shocks, the flow very near the wall will behave according to:

$$
u^{+}=f\left(y^{+}\right)
$$

The use of wall function in a computational flow solver allows fewer points to be placed near the wall: whereas the first grid point off the wall is typically placed at $y^{+}=1$, the wall function grid point spacing typically ranges from $y^{+}=15$ to $y^{+}=100$ near the wall. Using fewer points can significantly reduce computational costs. The first goal of this study is to judge the performance of wall functions within the Wind code.

This study also observes the performance of several turbulence models within the Wind code. Turbulence models are required to close the Reynolds-averaged Navier-Stokes (RANS) equations used by essentially all production CFD codes. They vary in complexity and robustness from simple zero-equation models, to single- and two-equation models, up to algebraic stress models and full Reynolds-stress models, in which each step up in complexity promises higher fidelity at higher costs. The second goal of this study is understand the performance of the Chien $K-\varepsilon$ and Mentor SST turbulence models within the Wind code.

Three geometries were selected in this investigation of turbulence model and wall function performance within Wind. First, incompressible flow over flat plate was analyzed as a benchmark boundary layer study. Next, the Buice-Eaton diffuser case was simulated. Incompressible flow through the diffuser experiences separation and reattachment, allowing the observation of a flow beyond the assumptions made by wall functions. Lastly, a dual-stream subsonic nozzle was studied to determine turbulence model and wall function performance in a "real-world" flow situation.

\section{Computational Resources}

Version 5 of the Wind ${ }^{2}$ code was used for the work considered here. Wind is a ReynoldsAveraged Navier-Stokes (RANS) code, developed and managed by the NPARC Alliance. The NPARC Alliance is a partnership between NASA Glenn Research Center, USAF Arnold Engineering Development Center, and The Boeing Company. The Wind code has matured as a multi-zone, structured grid compressible flow solver, offering a variety of turbulence models. These turbulence models include several zero-equation models, Spalart-Allmaras and other one-equation models, and the Chien $K-\varepsilon$ and Menter SST two-equation models. Additionally, wall functions may be used with these turbulence models or any of the turbulence models within Wind.

Grid sequencing was employed to speed up the convergence of the diffuser and nozzle geometries. One level of grid sequencing was used with the Buice-Eaton diffuser, and two levels of grid sequencing were used with the $3 \mathrm{BB}$ nozzle. The flat plate geometry converged quickly enough that grid sequencing was unnecessary.

To guarantee that the flow solution had converged, flow quantities were monitored in addition to the $\mathrm{L}^{2}$ residual. For the flat plate and diffuser cases, the convergence of the skin friction and the convergence of the velocity magnitude, turbulent kinetic, total temperature, and total pressure energy along vertical profiles were monitored. The convergence of the velocity magnitude, turbulent kinetic, total temperature, and total pressure energy along the centerline were monitored for the 3BB nozzle case. The solution was deemed converged when the monitored quantities did not change noticeably over the course of several hundred iterations.

These analyses were performed on two computer systems: an Intel Xeon-based workstation running Linux, and a multiprocessor SGI Origin3400 system.

\section{Flat-Plate Turbulence Model and Wall Function Study}

An incompressible flow over a flat plate with a fully-developed turbulent boundary layer was run using the Wind code. This flat plate flow has been documented by Wieghardt ${ }^{5}$, Coles, et al ${ }^{6}$, and Patel, et $\mathrm{al}^{7}$. More recently, a CFD validation study was conducted by Yoder and Georgiadis ${ }^{8}$ for the Chien $\mathrm{K}-\varepsilon$ turbulence model in Wind using the flat plate. This analysis simulated Mach 0.2 flow over a 1.0 $16.67 \mathrm{ft}$ long flat plate. The domain included a $1.0 \mathrm{ft}$ section before the leading edge of the plate to set up 
the flow. In Wind, the flow total pressure and total temperature of the flow were set at $14.7 \mathrm{lb} / \mathrm{in}^{2}$ and $530^{\circ} \mathrm{R}$, respectively.

\section{A. Flat Plate Grids and Cases}

Four grids were used: one developed for wall integration with a second grid point spacing corresponding to an average of $y^{+}=2$; and three grids with second point spacings of approximately $y^{+}=15$, 30, and 60. Each 2-D grid measured 111x81. The flat plate was run with Menter's SST and Chien's K- $\varepsilon$ turbulence models. The compressibility correction and variable $C_{\mu}$ options were disabled for the $K-\varepsilon$ turbulence model. Wall functions were also used in addition to full wall integration (even on grids with poor near-wall grid spacing). Table 1 details the parameters for each of the ten flat plate cases. Each case is denoted by a label of the form "FPnnWWT," in which "FP" denotes flat plate, "nn" is the second gridpoint $y^{+}$spacing, "WW" denotes whether wall integration (WI) or wall functions (WF) were used, and " $\mathrm{T}$ " denotes the turbulence model (S for SST or K for $K-\varepsilon$ ). For example, "FP30WIK" denotes that a flat plate simulation was performed using a grid spacing of $y^{+}=30$, wall integration, and the $K-\varepsilon$ turbulence model.

Table 1: Matrix of parametric studies with flat plate.

\begin{tabular}{|c|c|c|c|c|c|c|c|c|c|c|}
\hline Analysis & 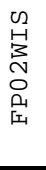 & 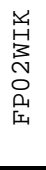 & 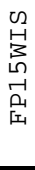 & 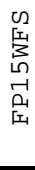 & 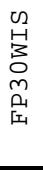 & 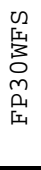 & 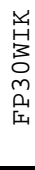 & 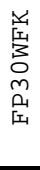 & 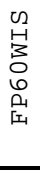 & 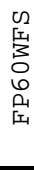 \\
\hline$y^{+}=2$ grid & $\mathrm{x}$ & $\mathrm{x}$ & & & & & & & & \\
\hline$y^{+}=15$ grid & & & $\mathrm{x}$ & $\mathrm{x}$ & & & & & & \\
\hline$y^{+}=30$ grid & & & & & $\mathrm{x}$ & $x$ & $\mathrm{x}$ & $\mathrm{X}$ & & \\
\hline$y^{+}=60$ grid & & & & & & & & & $\mathrm{x}$ & $\mathrm{x}$ \\
\hline Wall Functions & & & & $\mathrm{x}$ & & $\mathrm{x}$ & & $\mathrm{x}$ & & $\mathrm{x}$ \\
\hline SST & $\mathrm{x}$ & & $\mathrm{x}$ & $\mathrm{x}$ & $\mathrm{X}$ & $\mathrm{x}$ & & & $\mathrm{x}$ & $\mathrm{x}$ \\
\hline$K-\varepsilon, \operatorname{Var} C_{\mu}$ Off & & $\mathrm{x}$ & & & & & $\mathrm{x}$ & $\mathrm{x}$ & & \\
\hline
\end{tabular}

\section{B. Flat Plate Analyses Results}

Experimental results for the velocity profile and turbulent kinetic energy (TKE) profile through the boundary layer and skin friction along the plate were available to help validate the Wind results5,6. Figures $1 \mathrm{a}$ and $2 \mathrm{a}$ show the non-dimensionalized velocity, $u^{+}$, through the boundary layer at $R e_{x}=1.03 \mathrm{e}+7$. The Wind velocity profiles show very good agreement with the experimental data. The cases with large $y^{+}$values and run without wall functions disagree with the experimental data at the edge of the boundary layer. The non-dimensionalized turbulent kinetic energy, $k^{+}$, through the boundary layer at the location where $R e_{x}=1.03 \mathrm{e}+7$ is shown in Figure $1 \mathrm{~b}$ and $2 \mathrm{~b}$. When the TKE profiles are compared, it is observed that the solutions on grids with higher $y^{+}$values grid grossly over predict the amount of TKE very near the wall. The Case FP02WIK solution, shows good agreement with the data in regards to predicting the peak value of TKE near the wall, but then does not match the TKE farther up in the boundary layer $\left(50<y^{+}<100\right)$. In contrast, Case FP02WIS, shows poor agreement with the data near the wall, but good agreement farther up in the boundary layer.

The coefficient of skin friction,

$$
C_{f}=\frac{\tau_{w}}{\frac{1}{2} \cdot \rho \cdot U_{e}}
$$

was computed by cfpost using first-order differencing of $d u / d y$ in calculating wall shear stress,

$$
\tau_{w}=\mu \cdot \frac{d u}{d y}
$$

Second-order differencing is the default setting. Whereas first- and second-order differencing give similar predictions of skin friction on a wall integration grid (where the first several grid points are located in the linear region), first- and second-order differencing give significantly different predictions of skin friction on a wall function grid (where the first several grid point lie well outside of the linear region 
of the boundary layer). In fact, second-order differencing gives a falsely good prediction of skin friction, smoothing over the deficiencies of solving with wall integration on a wall function grid. First-order differencing is not as forgiving in this situation. The skin friction along the plate is presented in Figure 1c and 2c. The wall integration on the $y^{+}=2$ grid solutions (Cases FP02WIS and FP02WIK) and the wall function solutions (with the exception of Case FP60WFS) show good agreement with the data. Without the use of wall functions, the solutions on the wall function grids give poor predictions of the skin friction, up to $50 \%$ disagreement across the entire plate.

From the above comparisons, it was observed the wall integration solutions, Cases FP02WIS and FP02WIK, showed good agreement with the experimental results with some disagreement only in the TKE profiles. Further comparisons are made for these two cases to judge the turbulence model and wall function performance of the Wind code. Figures 3 and 4 show the $u$ and $v$ velocity profiles at a point of fully developed turbulent boundary layer flow. In general, the SST model and $K-\varepsilon$ turbulence models show good agreement with each other. It is clearly observed that large deviations exist when wall functions are not used on the $y^{+}=15,30$, and 60 grids. Figures 5-8 show the TKE and turbulent viscosity, $\mu_{t}$, through the boundary layer. The cases with larger $y^{+}$value grids show that wall functions are clearly necessary for good predictions of turbulence quantities. However, wall functions are unable to give good predictions of TKE and $\mu_{t}$ very near the wall. Also, the FP60WFS case shows that at the ability of wall functions to give good predictions breaks down by $y^{+}=60$ when the initial $y^{+}$value is greater than 60 .

Given these results, it can be concluded that the implementation of wall functions within the Wind code performs well on a flat plate for predicting skin friction and velocities for a zero-pressure gradient boundary layer. However, the wall functions were not able to predict turbulence quantities very near the wall. Furthermore, wall function performance suffers beyond $y^{+}=60$ when the first $y^{+}$value is greater than 60.

\section{Buice-Eaton Diffuser Turbulence Model and Wall Function Study}

In the flat plate study, the wall function cases demonstrated good agreement with the correct wall integration cases. This should be expected from such a benign case as a flat plate. The next set of analyses examines the performance of the wall functions (and turbulence models) for the more challenging case of a separated flow. For this set of analyses, the Buice-Eaton diffuser ${ }^{9}$ was used. The diffuser, illustrated in Figure 9, is a 2-dimensional, asymmetric diffuser in which incompressible, fully developed turbulent flow experiences smooth wall separation and reattachment. Buice and Eaton used the inflow channel height of $H=0.591$ inches as the reference length. The lower wall of the diffuser slopes down at $10^{\circ}$ over a distance of $21 \mathrm{H}$ and opens the diffuser height up to $4.7 \mathrm{H}$. The total pressure and total temperature at the inflow were set to $14.7 \mathrm{lb} / \mathrm{in}^{2}$ and $530^{\circ} \mathrm{R}$, respectively. The downstream static pressure was nominally set at $14.65 \mathrm{lb} / \mathrm{in}^{2}$ and was adjusted to obtain a bulk velocity of $65.6 \mathrm{ft} / \mathrm{sec}$ at the entrance of the diffuser, as in the experiment. The bulk velocity is defined by

$$
U_{b}=\left(\frac{1}{H}\right) \cdot \int_{0}^{H} u \cdot d y
$$

and is computed at the entrance of the diffuser. The flow into the diffuser is approximately Mach 0.058.

\section{A. Buice-Eaton Diffuser Grids and Cases}

A total of ten cases were run with the Buice-Eaton diffuser, using $y^{+}$values at the wall of $1,15,30$ and 60 , the Menter SST and the Chien $K-\varepsilon$ turbulence models, and wall functions enabled and disabled. Table 2 details the parameters of each of the ten cases. (Similar to the flat plate case, the diffuser analysis cases are label as "BEnnWWT," in which "BE" denotes the case as a Buice-Eaton diffuser analysis.) The computational domain extended $110 \mathrm{H}$ upstream of the diffuser to allow fully developed turbulent boundary layers to form on the upper and lower surfaces before the flow entered the diffuser. The total grid size for all the grids was 341x81 points. 
Table 2: Matrix of parametric studies with the Buice-Eaton diffuser.

\begin{tabular}{|c|c|c|c|c|c|c|c|c|c|c|}
\hline Analysis & $\begin{array}{l}02 \\
0 \\
-1 \\
3 \\
-1 \\
0 \\
\text { y1 } \\
0\end{array}$ & 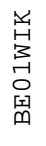 & 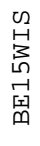 & 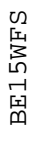 & 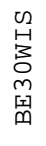 & 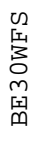 & 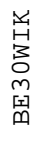 & 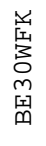 & $\begin{array}{l}02 \\
1 \\
0 \\
3 \\
0 \\
6 \\
1 \\
9 \\
9\end{array}$ & $\begin{array}{l}\text { o } \\
\text { 피 } \\
0 \\
0 \\
0 \\
\text { 됨 }\end{array}$ \\
\hline$y^{+}=1$ grid & $\mathrm{x}$ & $\mathrm{X}$ & & & & & & & & \\
\hline$y^{+}=15$ grid & & & $\mathrm{X}$ & $\mathrm{x}$ & & & & & & \\
\hline$y^{+}=30$ grid & & & & & $\mathrm{X}$ & $\mathrm{X}$ & $\mathrm{X}$ & $\mathrm{X}$ & & \\
\hline$y^{+}=60$ grid & & & & & & & & & $\mathrm{X}$ & $\mathrm{x}$ \\
\hline Wall Functions & & & & $\mathrm{x}$ & & $\mathrm{X}$ & & $\mathrm{X}$ & & $\mathrm{x}$ \\
\hline SST & $\mathrm{x}$ & & $\mathrm{X}$ & $\mathrm{x}$ & $\mathrm{x}$ & $\mathrm{X}$ & & & $\mathrm{x}$ & $\mathrm{x}$ \\
\hline$K-\varepsilon$, Var $C_{\mu}$ off & & $\mathrm{X}$ & & & & & $\mathrm{x}$ & $\mathrm{X}$ & & \\
\hline
\end{tabular}

\section{B. Buice-Eaton Diffuser Analyses Results}

The experimental results show that separation occurred at $7.4 \mathrm{H}$ downstream of the entrance into the diffuser. Reattachment took place at 29.2H. Figures 10-12 show the skin friction along the lower and upper walls of the diffuser. Table 3 gives the separation and reattachment points along the lower wall for each case. Both $y^{+}=1$ grid cases (Cases BE01WIS and BE01WIK) predicted separation earlier than what was seen in the experiment. However, there is pretty good agreement between most of the SST model cases for where the flow reattaches in the diffuser, roughly $29.5 \mathrm{H}$. For SST cases, only the two $y^{+}=60$ cases (Cases BE60WIS, BE60WFS) differ at reattachment, and Case BE60WIS fails to predict separation. It should be noted that the $K-\varepsilon$ model predicts a considerably earlier reattachment on the lower wall of the diffuser. Furthermore, the $K-\varepsilon$ model predicts flow separation of the upper wall of the diffuser, which is not observed in the experimental data. Plots of the velocity contours and streamlines in Figure 13 show a vast difference between the flowfields predicted by the SST and $K-\varepsilon$ models. The region of separated flow is clearly recognizable for the SST turbulence model. In contrast, it is only with the help of Figure 11 that we know the $K-\varepsilon$ turbulence model predicts any separation, because the $K-\varepsilon$ model predicts the region of separated flow to be very thin and close to the wall. Figure 14 shows plots of the TKE contours as predicted by the SST and $K-\varepsilon$ models: the effect of the $K-\varepsilon$ turbulence model's poor performance is observed. The axial velocity profiles, normalized by the bulk velocity $U_{b}$, are plotted in Figures 15 and 16. They show that the SST model agrees with the experimental data better than the $K-\varepsilon$ model, even up to the $y^{+}=30$ grid, with and without wall functions. The SST $y^{+}=60$ grid is clearly beyond the usefulness of wall functions for this flow.

Table 3: Buice-Eaton diffuser lower wall separation and reattachment points.

\begin{tabular}{|l|c|c|}
\hline Case & $\begin{array}{c}\text { Separation } \\
\text { Point }[\mathbf{x} / \mathbf{H}]\end{array}$ & $\begin{array}{c}\text { Reattachment } \\
\text { Point }[\mathbf{x} / \mathbf{H}]\end{array}$ \\
\hline Experiment & 7.4 & 29.2 \\
\hline BE01WIS & 2.55 & 29.52 \\
\hline BE01WIK & 0.72 & 20.49 \\
\hline BE15WIS & 2.61 & 29.72 \\
\hline BE15WFS & 2.48 & 29.43 \\
\hline BE30WIS & 7.37 & 30.43 \\
\hline BE30WFS & 5.52 & 28.61 \\
\hline BE30WIK & 8.04 & 22.77 \\
\hline BE30WFK & 3.61 & 21.94 \\
\hline BE60WIS & N/A & N/A \\
\hline BE60WFS & 11.90 & 25.73 \\
\hline
\end{tabular}

From this set of parametric studies on the Buice-Eaton diffuser, a couple of conclusions can be made. First, the SST turbulence model does a much better job of predicting the flow in this diffuser than the Chien $K-\varepsilon$ turbulence model: the $K-\varepsilon$ model performs quite poorly in the presence of an adverse pressure gradient. The only fault is that the SST model gives a more conservative prediction for when separation occurs. Next, Wind's wall functions, paired with the SST turbulence model, are not a good 
choice for separated flow: flow separation is delayed on the $y^{+}=30$ grid and the results are poor on the $y^{+}=60$ grid.

\section{3BB Nozzle CFD Study}

The last set of analyses was performed on the 3BB nozzle configuration, of which experimental was presented by Saiyed and Bridges ${ }^{10}$. The 3BB nozzle is a separate flow nozzle representative of nozzles found on modern high-bypass ratio turbofan engines. The diameter of the nozzle is taken as the diameter of the secondary flow, which is $D=9.822 \mathrm{in}$. The nozzle was tested experimentally with a freestream Mach number of 0.28 , static pressure of $14.4 \mathrm{lb} / \mathrm{ft}^{2}$, and static temperature of $529.67^{\circ} \mathrm{R}$. The primary flow of the $3 \mathrm{BB}$ nozzle had a total pressure of $24.193 \mathrm{lb} / \mathrm{ft}^{2}$ and a total temperature of $1500^{\circ} \mathrm{R}$. Lastly, the secondary flow had a total pressure of $26.353 \mathrm{lb} / \mathrm{ft}^{2}$ and a total temperature of $600^{\circ} \mathrm{R}$. Like the previous two studies, a number of $3 \mathrm{BB}$ nozzle cases were run with various combinations of wall functions/wall integration and turbulence models.

\section{A. 3BB Nozzle Grids and Cases}

Two grids were used for the computational analyses of the 3BB nozzle. The first grid was a wall function grid used previously by Koch and Bridges ${ }^{11}$ and is pictured in Figure 17. This grid was designed for the use of wall functions and had a nominal second grid point spacing of about $y^{+}=15$. However, because of the large difference in temperatures between the primary- and secondary-flow nozzles, the $y+$ value along the secondary-flow nozzle was closer to 30, and rising as high as 60 to 70 near the exit. The wall function grid extends approximately 15 nozzle diameters downstream of the nozzle. (Note that one 3BB nozzle diameter was equal to $D=0.8024 \mathrm{ft}$, the diameter of the secondary-flow nozzle.) Near the nozzle, the grid extended about 1.25 diameters radially outward from the nozzle. At the outflow, the grid extends 2.5 diameters radially outward. The wall function grid had approximately 85,000 points. The second grid, pictured in Figure 18, was designed for full wall integration, and therefore had a nominal second grid point spacing of $y^{+}=1$. The wall integration grid had the same bounds as the wall function grid and had 117,600 points. Both grids run axisymmetrically with Wind.

Typically, grids for nozzle flows extend 10 to 20 diameters radially and 30 to 60 diameters downstream, so there was some concern that the computational domain may not have been large enough. Several analyses were run (in addition to those presented in this paper) in which the grid was extended to 15 diameters radially and 60 diameters axially. The results were identical to those of the original computational domain size, and the original domain size was concluded to be adequate.

\section{B. 3BB Nozzle Analyses Results}

A summary of the set of parametric studies performed using the 3BB nozzle is provided in Table 4. The different cases are labeled in a similar fashion as the flat plate and diffuser cases were earlier in this report. In addition to running the default $K-\varepsilon$ turbulence model with no corrections, several cases were run with the variable $C_{\mu}$ correction $^{12}$ enabled, which is the default for Wind version 5 . Typical contours of the velocity magnitude and TKE are shown in Figure 19. The results of the Case 3BB15WFK $\mu$ were compared to the experimental data from Saiyed and Bridges ${ }^{10}$. The non-dimensionalized velocity and TKE profiles downstream of the 3BB nozzle are shown in Figures 20 and 21, respectively. The Wind results demonstrate reasonable agreement with the experimental data near the nozzle exit. Farther downstream, at $x / D=5$, however, the Wind solutions fail to predict the large rise in TKE observed in the experimental results.

The centerline velocity profile is plotted in Figure 22 for the experimental data and Case $3 \mathrm{BB} 15 \mathrm{WFK} \mu$. Poor agreement is observed between the experimental results and the computational solution. Because the $3 \mathrm{BB}$ nozzle is a typical dual-stream nozzle geometry, including a plug, it can be reasoned that the low centerline velocity within the first few diameters of the nozzle was a result of Wind not resolving the wake region behind the plug correctly. Whereas for a single stream nozzle without a plug comparing the centerline flow properties of the experiment and CFD would probably show good agreement, comparing centerline flow qualities for a nozzle with a plug may not be the best way to judge 
the CFD solution. One aspect of the centerline velocity plot that is not surprising is that Wind predicts the potential core to be four diameters longer than what is seen in the experiment. Likewise, the computational solutions predict that the peak value of $T K E$, as plotted in Figure 23, occurs nearly three diameters downstream of the peak TKE found experimentally. This was expected as a number of computational nozzle flow analyses of subsonic jets over-predict the length of the potential core ${ }^{13}$. Currently, one focus of the CFD community is to develop flow models that better predict the initial jet development region and resultant breakdown of the potential core in a nozzle flow. Even though the CFD does not show good agreement with the experiment along the centerline, plotting flow quantities along the centerline is a good way to compare computational solutions with each other.

Table 4: Matrix of parametric studies using the 3BB nozzle.

\begin{tabular}{|c|c|c|c|c|c|c|c|c|}
\hline Analysis & 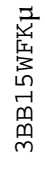 & 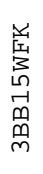 & 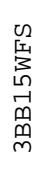 & 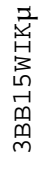 & 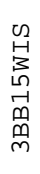 & 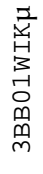 & 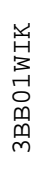 & $\begin{array}{l}\text { N } \\
1 \\
3 \\
-1 \\
-1 \\
0 \\
9 \\
m \\
m\end{array}$ \\
\hline Wall Function grid $\left(y^{+} \sim 15\right)$ & $\mathrm{x}$ & $\mathrm{X}$ & $\mathrm{X}$ & $\mathrm{x}$ & $\mathrm{X}$ & & & \\
\hline Wall integration grid $\left(y^{+}=1\right)$ & & & & & & $\mathrm{X}$ & $\mathrm{X}$ & $\mathrm{x}$ \\
\hline Wall Functions enabled & $\mathrm{X}$ & $\mathrm{X}$ & $\mathrm{X}$ & & & & & \\
\hline$K-\varepsilon, \operatorname{Var} C_{\mu}$ On & $\mathrm{X}$ & & & $\mathrm{x}$ & & $\mathrm{X}$ & & \\
\hline$K-\varepsilon, \operatorname{Var} C_{\mu}$ off & & $\mathrm{X}$ & & & & & $\mathrm{X}$ & \\
\hline SST & & & $\mathrm{X}$ & & $\mathrm{X}$ & & & $\mathrm{x}$ \\
\hline
\end{tabular}

\section{Wall Functions Study}

The effects of the use of wall functions are observed for both the SST and $K-\varepsilon$ turbulence models. For this study, Cases 3BB15WFK, 3BB15WIK, and 3BB01WIK were compared for the $K-\varepsilon$ turbulence model and Cases 3BB15WFS, 3BB15WIS, and 3BB01WIS were compared for the SST turbulence model. The study compared the results of the wall function grid (created for use with wall functions) with and without the use of wall functions and the wall integration grid (created for full integration to the wall). Figures 24 and 25 present the velocity magnitude, total pressure, and total temperature along the centerline for both turbulence models. For the $K-\varepsilon$ model, both wall functions and wall integration on the wall function grid delay the velocity magnitude and total pressure peaks downstream by about half of a diameter. The total temperature potential core length is also increased by about half of a diameter. The use of wall functions and the wall function grid seem to have little effect on the centerline properties when the SST model is used.

The centerline TKE and maximum TKE are plotted in Figures 26 and 27 for each turbulence model. The differences between the use of the wall function grid, wall functions, and wall integration are more significant in the TKE plots, than those of the mean flow properties in Figures 24 and 25. In all cases, the use of wall functions delays the dissipation of TKE, causing the flow to have a higher peak value of TKE than those analyses performed without wall functions. Furthermore, when wall functions are not used on a grid designed for use with wall functions, there is more dissipation of TKE, causing the flow to have a lower peak value of TKE. The effect of the wall functions on the maximum value of TKE is approximately seven to nine percent. It should also be noted that the $K-\varepsilon$ model predicts generally higher levels of TKE than the SST model.

Boundary layer profiles of velocity $(u)$ and turbulent viscosity $\left(\mu_{T}\right)$ in the primary flow nozzle are plotted in Figures 28 and 29 for each turbulence model. The differences in the velocity profiles are rather small, so it is difficult to determine what effect the wall functions have on the flow in this region. The low values of turbulent viscosity suggest that the flow is just past transition at this point in the primary nozzle and that the use of wall functions may not be that important for this particular case. However, for other nozzle simulations where internal boundary layer effects are more significant, the impact of wall functions may have a more substantial influence on the calculated flowfield. 


\section{Turbulence Model Study}

A second parametric study compared turbulence models. The Chien $K-\varepsilon$ turbulence model, with and without a variable $C_{\mu}$, and Menter's SST turbulence model are compared on the 3BB nozzle flow using the Koch wall function grid and the WI-1 wall integration grid. This corresponds to Cases 3BB15WFK $\mu$, 3BB15WFK, and 3BB15WFS using wall functions, and Cases 3BB01WFK $\mu, 3 B B 01 W F K$, and 3BB01WFS with wall integration. The centerline velocity magnitude, centerline TKE, and maximum TKE are plotted for each turbulence model in Figures 30 and 31 for the wall function and wall integration grids, respectively. The same behaviors are observed whether wall functions or wall integration are used. In the centerline velocity, the SST model and the $K-\varepsilon$ model using the variable $C_{\mu}$ show good agreement with each other, whereas the $K-\varepsilon$ model with constant $C_{\mu}$ predicts a slightly higher maximum potential core velocity and a potential core breakdown about one diameter farther downstream than the previous two models. The plots of the centerline values of TKE show that none of the three turbulence models agree with each other after $x / D=7$, where each shows a different increase in TKE. While the peak value of the centerline TKE of Cases 3BB15WFK and 3BB01WIK does agree with the experimental results, these two CFD cases solve the rise in centerline TKE incorrectly when compared to the experimental data. When the maximum value of TKE is compared for the three turbulence models, all three turbulence models predict maximum values of TKE $20 \%$ to $30 \%$ less than the experiment. The SST model and $K-\varepsilon$ model with constant $C_{\mu}$ show good agreement with each other, while the $K-\varepsilon$ model with variable $C_{\mu}$ predicts a peak value of maximum TKE one diameter farther downstream. A comparison of the downstream TKE profiles is presented in Figure 32 for the wall function and wall integration analyses. As observed earlier, the Wind results fail to predict the rise in TKE seen in the experiment at $x / D=5$. Near the nozzle, the three turbulence models show good agreement. Farther downstream, the turbulence models show the same level of differences observed in the centerline and maximum TKE plots.

\section{Conclusions}

Wall functions allow the computer analyst to trade some level of fidelity for reduced computational costs in regions of the flow where wall functions are valid. This is accomplished by assuming attached flows that adhere to the law of the wall. As presented in the flat plate and 3BB nozzle studies, the use of wall functions can produce good predictions of flowfield properties for much of the flow when the flow is attached. However, wall functions cannot predict the flow properties very near the wall as well as full wall integration. Furthermore, it was shown in the Buice-Eaton diffuser case that wall functions perform poorly when flow separation does exist. Only full wall integration gave satisfactory predictions of the flow field associated with separation and reattachment.

Regarding turbulence models, the SST and $K-\varepsilon$ models generally work well for zero-pressure gradient flow. In a flow with an adverse pressure gradient, the SST model performed better than the $K-\varepsilon$ model: while both models gave conservative predictions for separation and reattachment, the $K-\varepsilon$ model grossly underpredicted the size of the separated region. More stratification between turbulence models was exhibited in the $3 \mathrm{BB}$ nozzle flow, with the $K-\varepsilon$ model with variable $C_{\mu}$ predicting significantly more turbulence than the other two models. Yet, none of the turbulence models were able to correctly predict the breakdown of the potential core downstream of the nozzle. Further understanding the strengths and limitations of turbulence models will help the computer analyst acquire more reliable predictions.

\section{Acknowledgements}

This work was supported by the Quiet Aircraft Technology project.

\section{References}

${ }^{1}$ Nelson, C. C., and Power, G. D., “CHSSI Project CFD-7: The NPARC Alliance Flow Simulation System, “ AIAA Paper 2001-0594, January 2001.

2 The Wind User's Guide Version 5, User Manual, The NPARC Alliance, Cleveland, OH. http://www.grc.nasa.gov/WWW/winddocs/wind5.0/index.html. 
${ }^{3}$ Mani, M., "A Compressible Wall Function for Steady and Unsteady Flow Applications," 17th AIAA Applied Aerodynamics Conference, AIAA Paper 99-3216, June 1999.

${ }^{4}$ White, F. M. and Christoph, G. H., "A Simple Theory for Two-Dimensional Compressible Turbulent Boundary Layer," Journal of Basic Engineering, Vol. 94, 1972, pp. 636-642.

5 Wieghardt, K. and Tillman, W., "On the Turbulent Friction Layer for Rising Pressure," NACA TM-1314, 1951.

${ }^{6}$ Coles, D. E., and Hirst, E. A., editors, Computation of Turbulent Boundary Layers - 1968 AFOSR-IFPStanford Conference, Vol. 2, Stanford University, CA, 1969.

7 Patel, V. C., Rodi, W., and Scheuerer, G., "Turbulence Models for Near-Wall and Low-Reynolds Number Flows: A Review," AIAA Journal, Vol. 23, No. 9, Sept. 1985, pp. 1308-1319.

8 Yoder, D. A., and Georgiadis, N. J., "Implementation and Validation of the Chien k-epsilon Turbulence Model in the WIND Navier-Stokes Code," 37th AIAA Aerospace Sciences Meeting and Exhibit, AIAA 99-0745, Jan. 1999.

9 Buice, C. U. and Eaton, J. K., "Experimental Investigation of Flow Through an Asymmetric Plane Diffuser," J. Fluids Engineering, Vol. 122, June 2000, pp. 433-435.

${ }^{10}$ Saiyed, N. H. and Bridges, J. E., "Tabs and Mixers for Reducing Low Bypass Ratio Jet Noise," 5th AIAA/CEAS Aeroacoustics Meeting and Exhibit, AIAA Paper 99-1996, May 1996.

${ }^{11}$ Koch, L. D., Bridges, J., and Khavaran, A., "Flowfield Comparisons from Three Navier-Stokes Solvers for an Axisymmetric Separate Flow Jet," NASA TM-2002-21350, February 2002.

${ }^{12}$ Rodi, W., and Scheuerer, G., "Scrutinizing the k-epsilon Turbulence Model Under Adverse Pressure Gradient Conditions," Transactions of the ASME Journal of Fluids Engineering, Vol. 108, pp. 174179, 1986.

${ }^{13}$ Georgiadis, N. J., Rumsey, C. L., Yoder, D. A., and Zaman, K. B. M. Q., “Effects of RANS Turbulence Modeling on Calculation of Lobbed Nozzle Flowfields," 41st AIAA Aerospace Sciences Meeting and Exhibit, AIAA 2003-1271, Jan. 2003. 


\section{Figures}

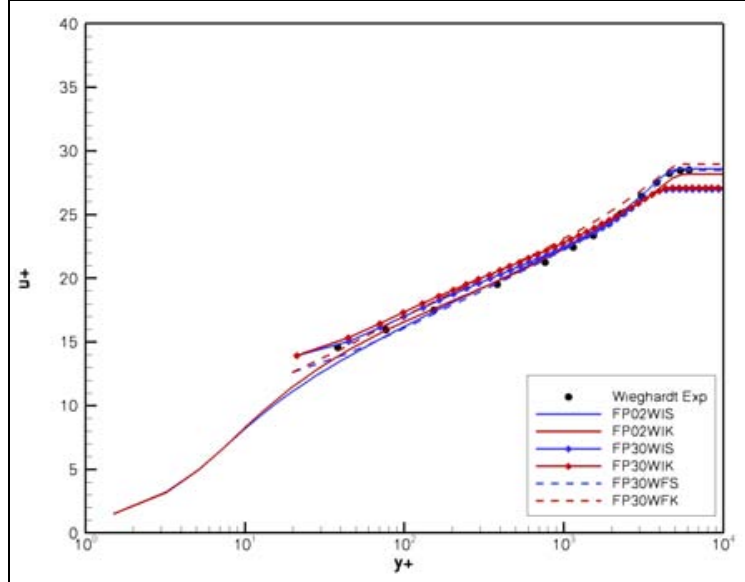

(a) $u^{+}$through boundary layer at $R e_{x}=1.03 \mathrm{e}+7$

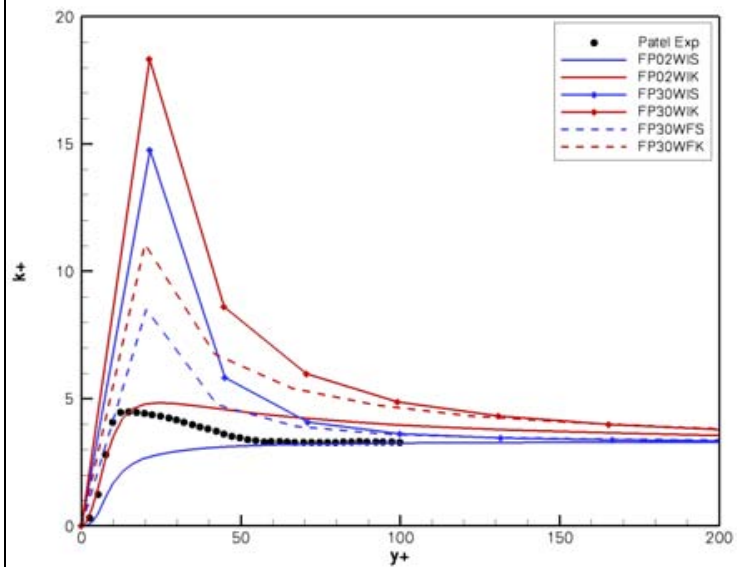

(b) $k^{+}$through boundary layer at $R e_{x}=1.03 \mathrm{e}+7$

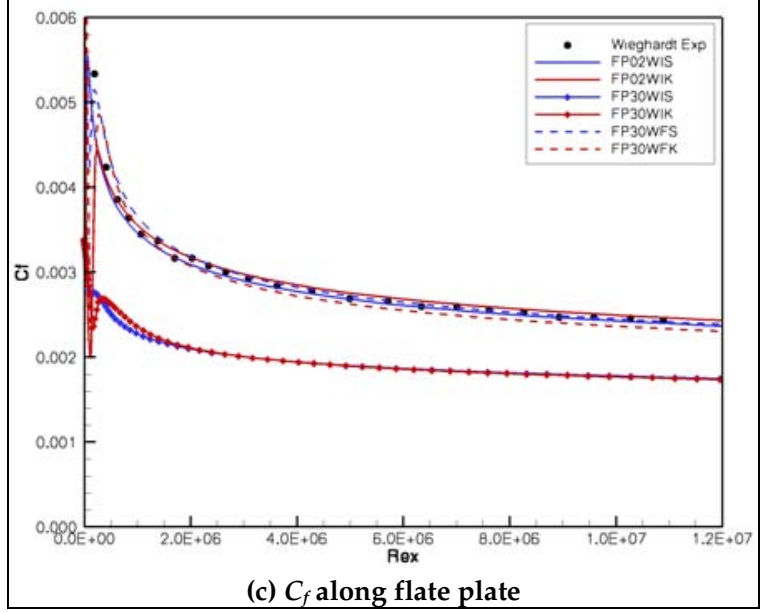

Figure 1: Comparison of flat plate analyses with experimental results; turbulence model comparison.

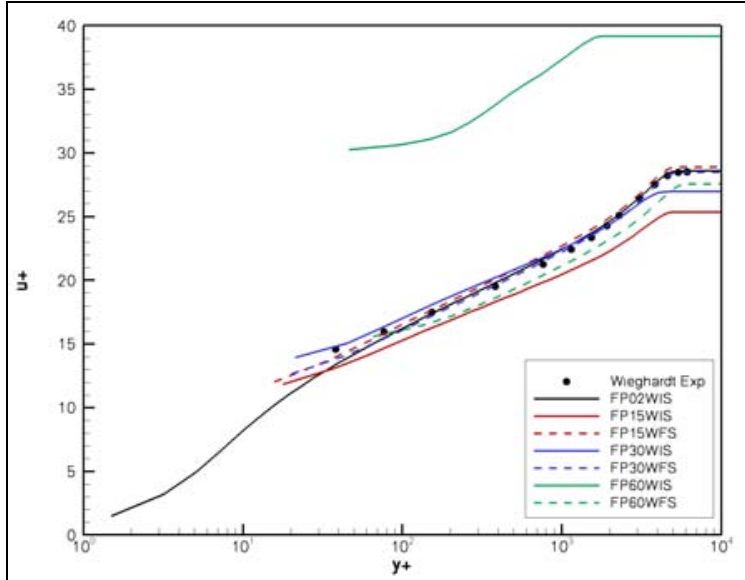

(a) $u^{+}$through boundary layer at $R e_{x}=1.03 \mathrm{e}+7$

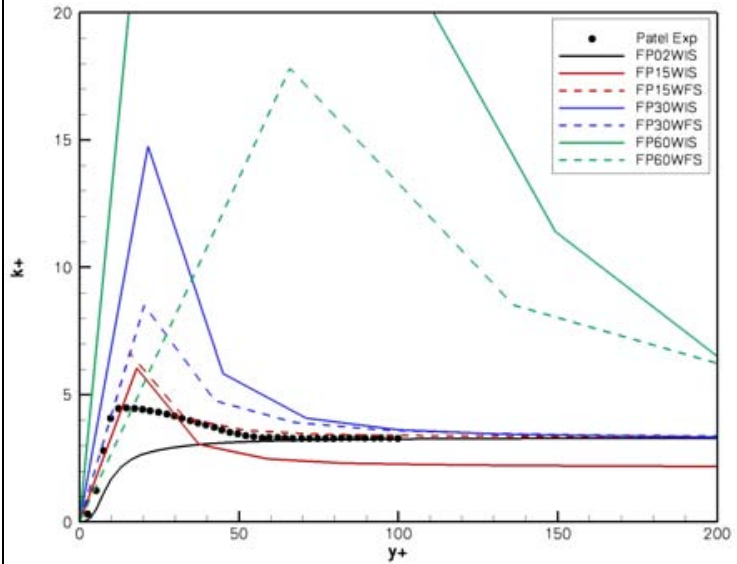

(b) $k^{+}$through boundary layer at $R e_{x}=1.03 \mathrm{e}+7$

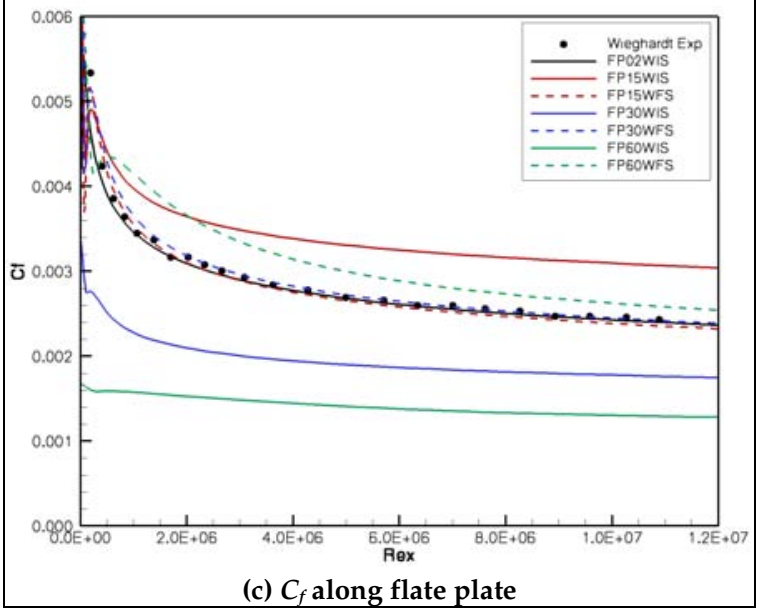

Figure 2: Comparison of flat plate analyses with experimental results; wall function/wall integration comparison. 


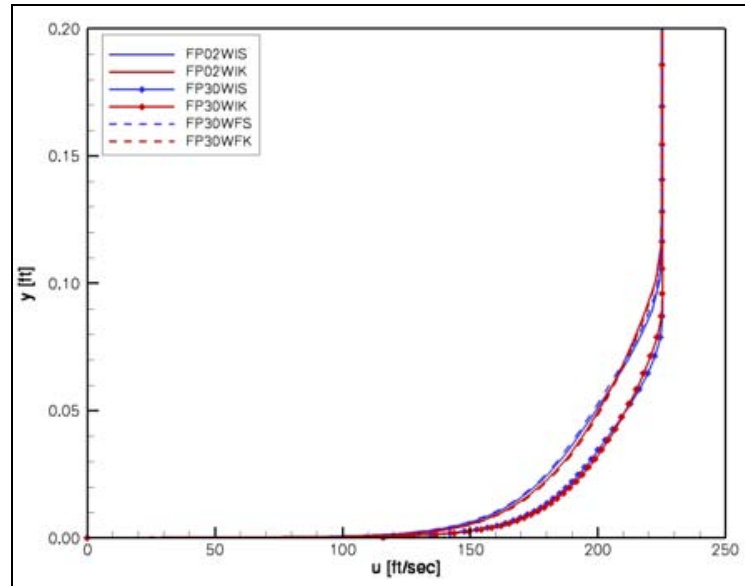

(a) $u$ component of velocity

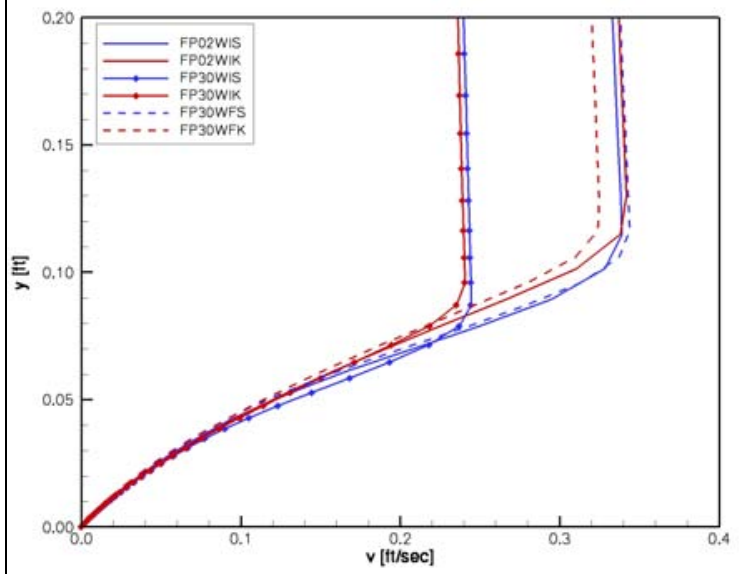

(b) $v$ component of velocity

Figure 3: Flat plate velocity profiles at $R e_{x}=1.03 \mathrm{e}+7$; turbulence model comparison.

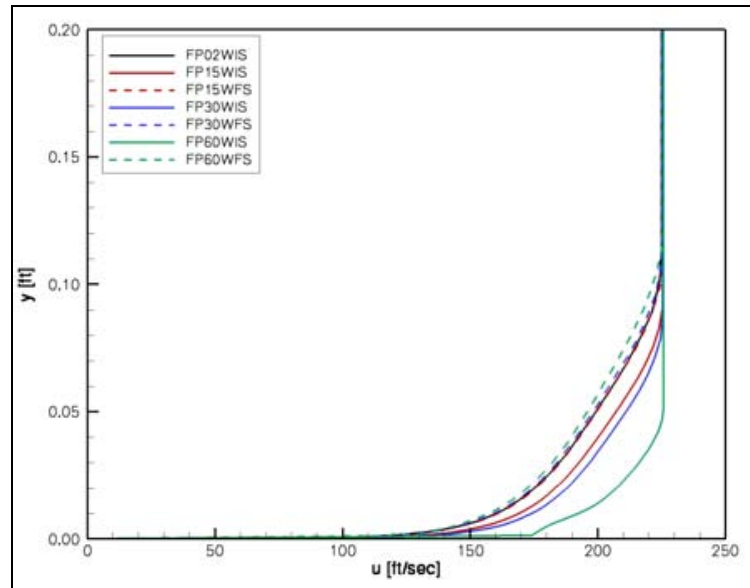

(a) $u$ component of velocity

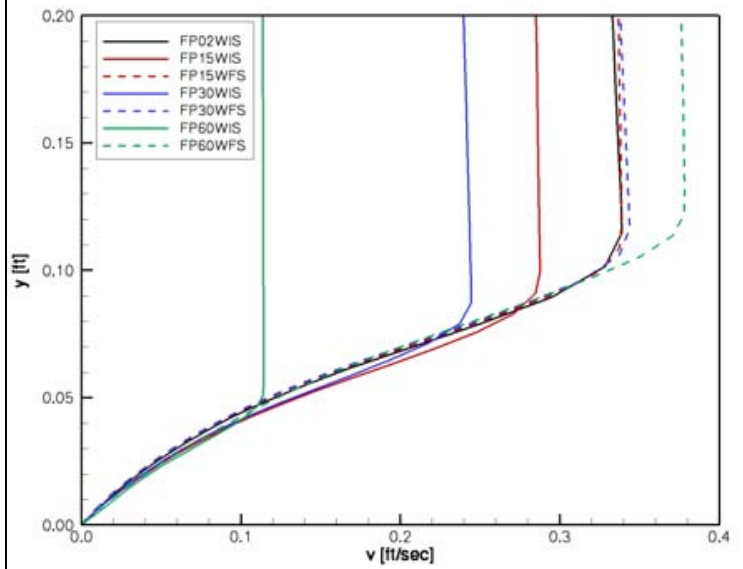

(b) $v$ component of velocity

Figure 4: Flat plate velocity profiles at $R e_{x}=1.03 e+7$; wall function/wall integration comparison. 


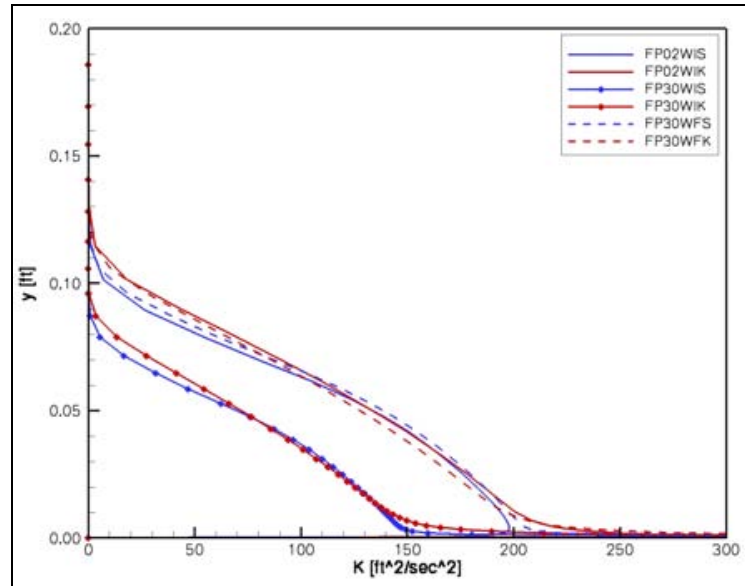

(a) TKE through boundary layer

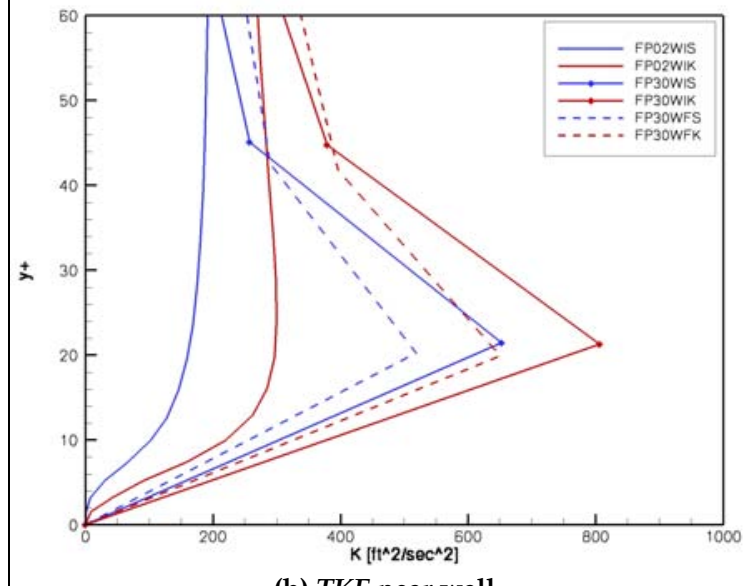

(b) TKE near wall

Figure 5: Flat plate $T K E$ at $R e_{x}=1.03 \mathrm{e}+7$; turbulence model comparison.

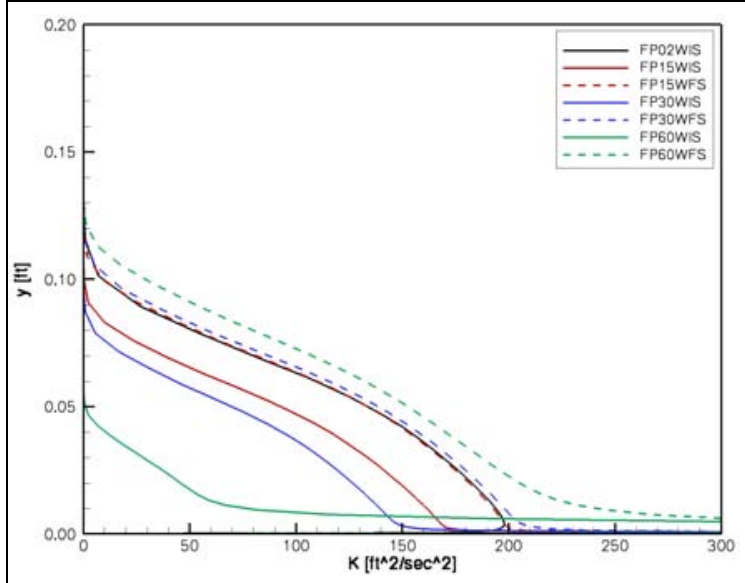

(a) TKE through boundary layer

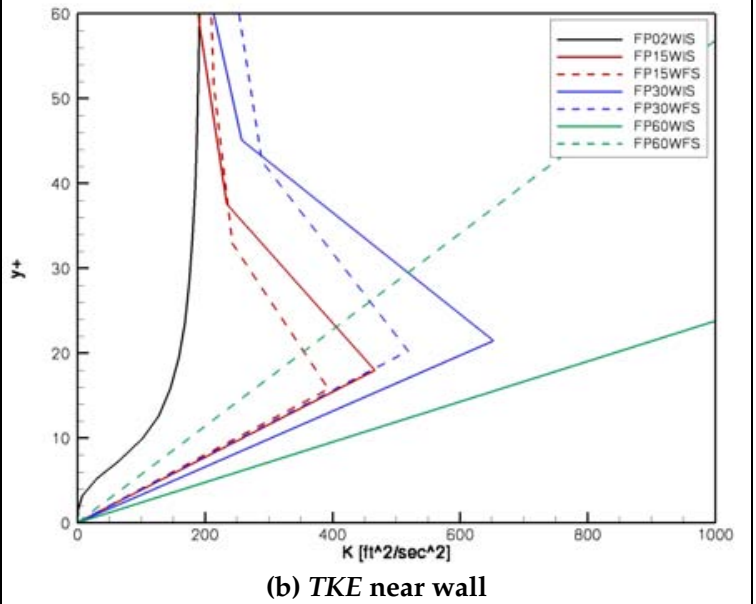

Figure 6: Flat plate $T K E$ at $R e_{x}=1.03 \mathrm{e}+7$; wall function/wall integration comparison. 


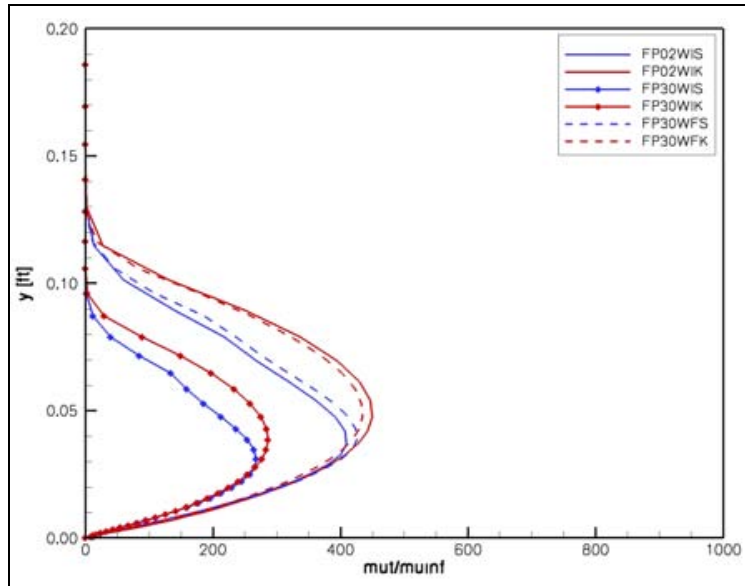

(a) $\mu_{t}$ through boundary layer

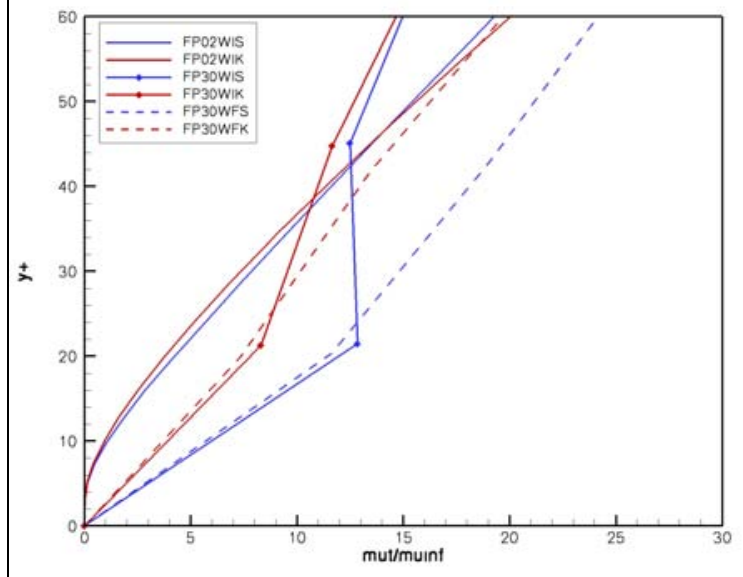

(b) $\mu_{t}$ near wall

Figure 7: Flat plate turbulent viscosity at $R e_{x}=1.03 \mathrm{e}+7$; turbulence model comparison.

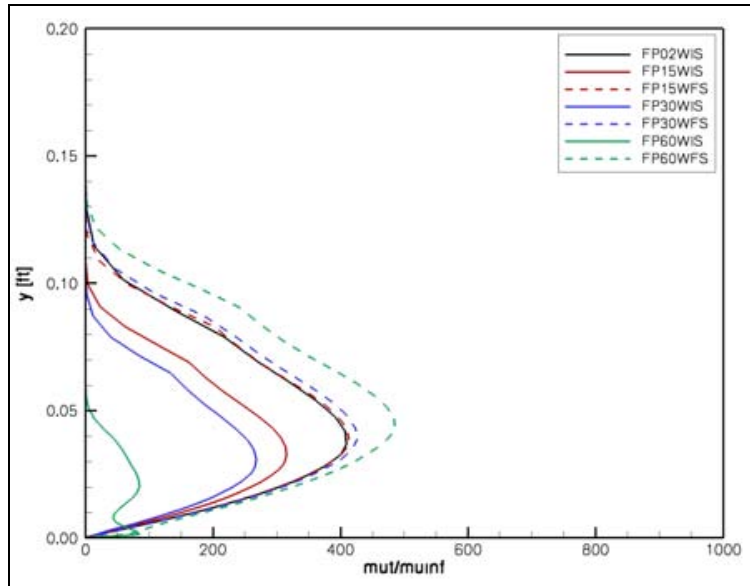

(a) $\mu_{t}$ through boundary layer

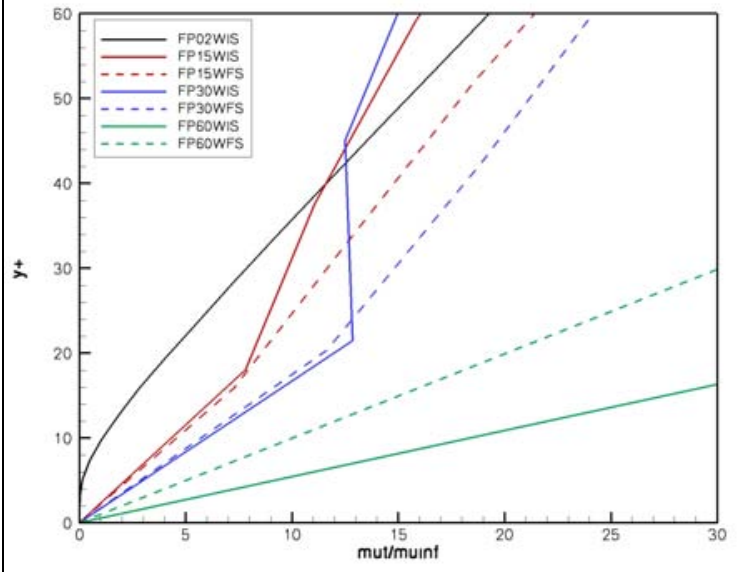

(b) $\mu_{t}$ near wall

Figure 8: Flat plate turbulent viscosity at $R e_{x}=1.03 \mathrm{e}+7$; wall function/wall integration comparison.

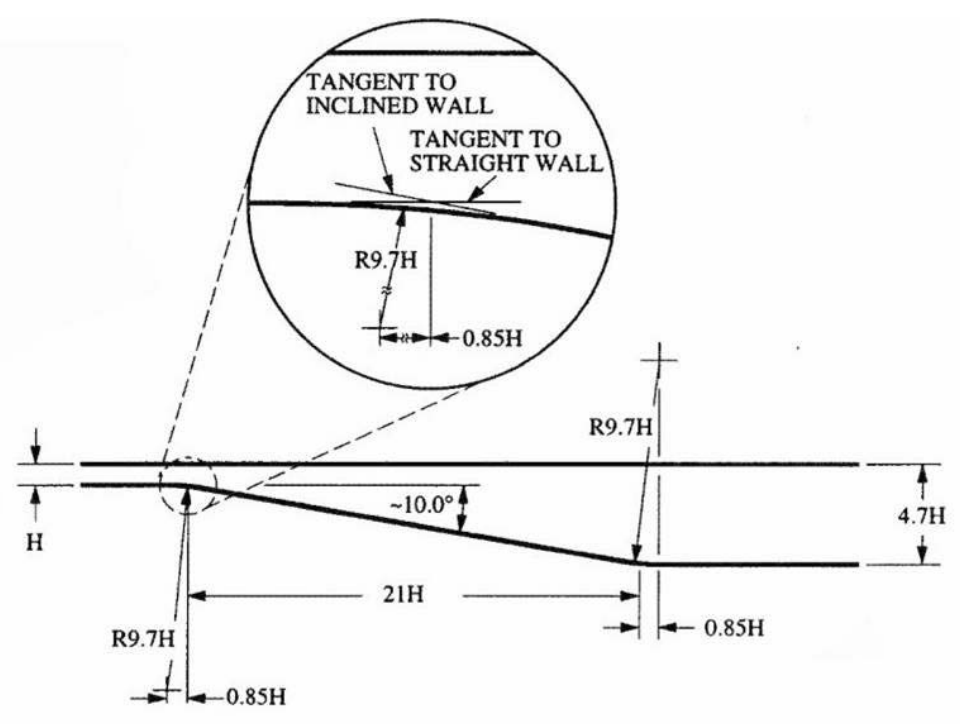

Figure 9: Schematic of Buice-Eaton diffuser'. 


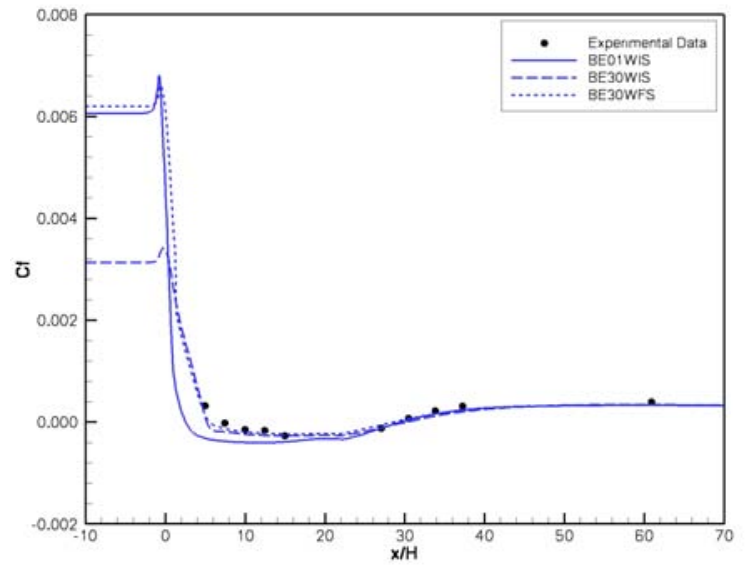

(a) Lower wall

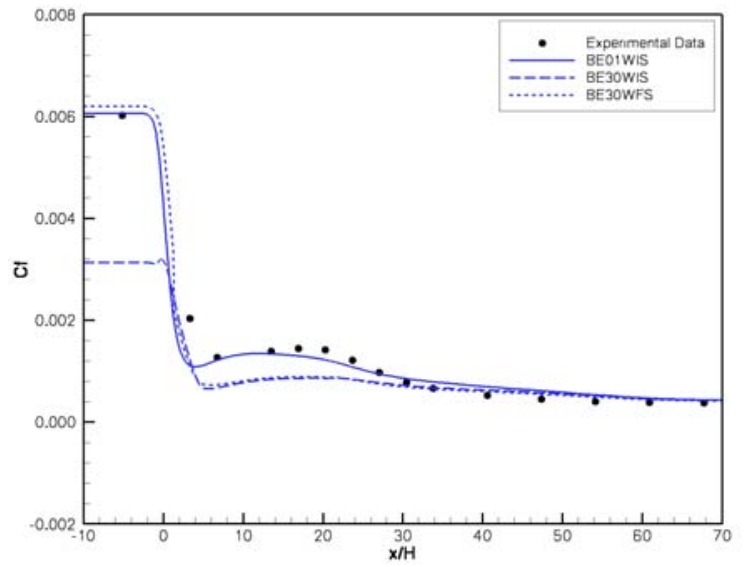

(b) Upper wall

Figure 10: Skin friction along upper and lower wall of Buice-Eaton diffuser. SST turbulence model.

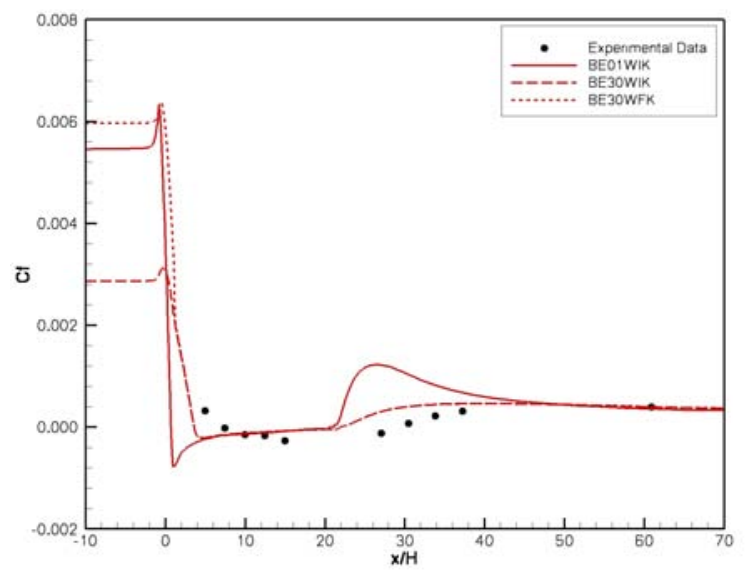

(a) Lower wall

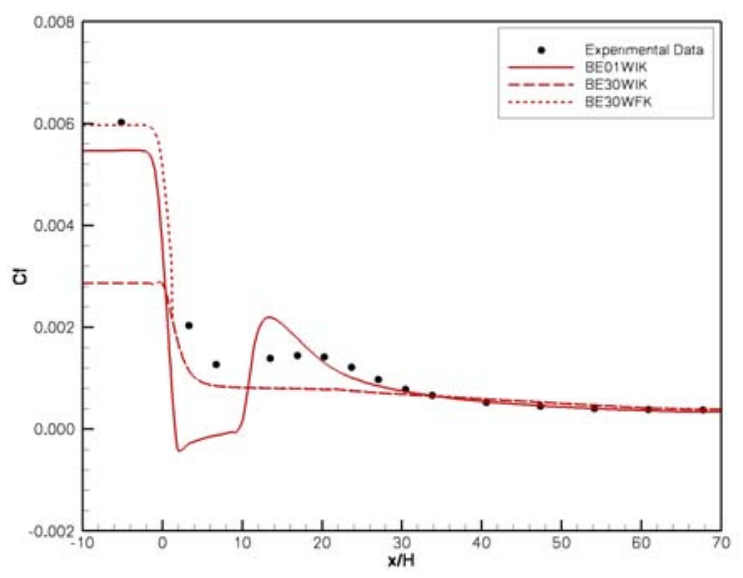

(b) Upper wall

Figure 11: Skin friction along upper and lower wall of Buice-Eaton diffuser. $K-\varepsilon$ turbulence model

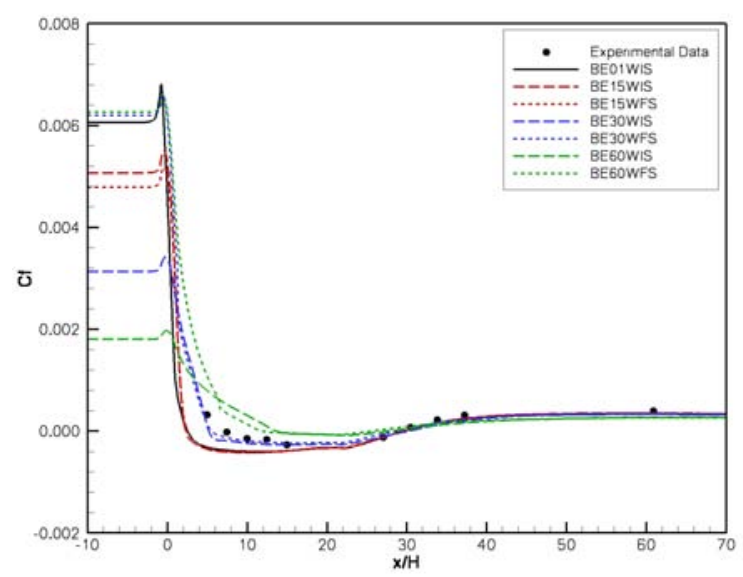

(a) Lower wall

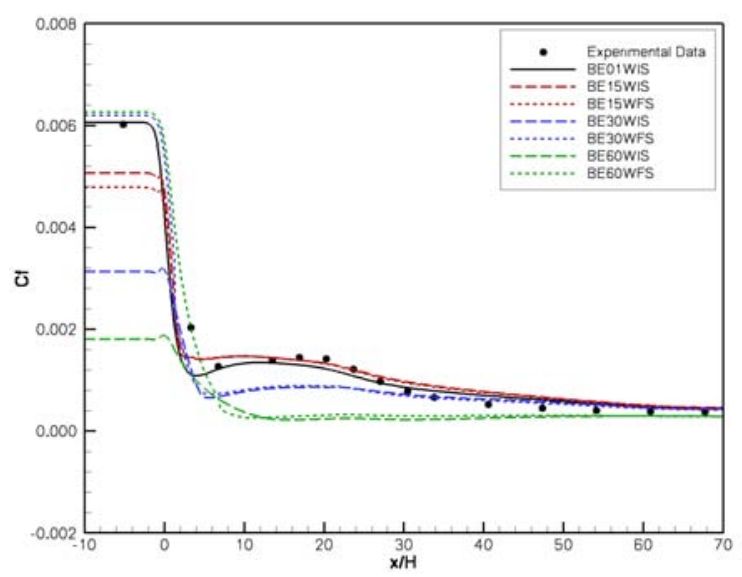

(b) Upper wall

Figure 12: Skin friction along lower and upper walls of Buice-Eaton diffuser. Wall functions, wall integration compared. 


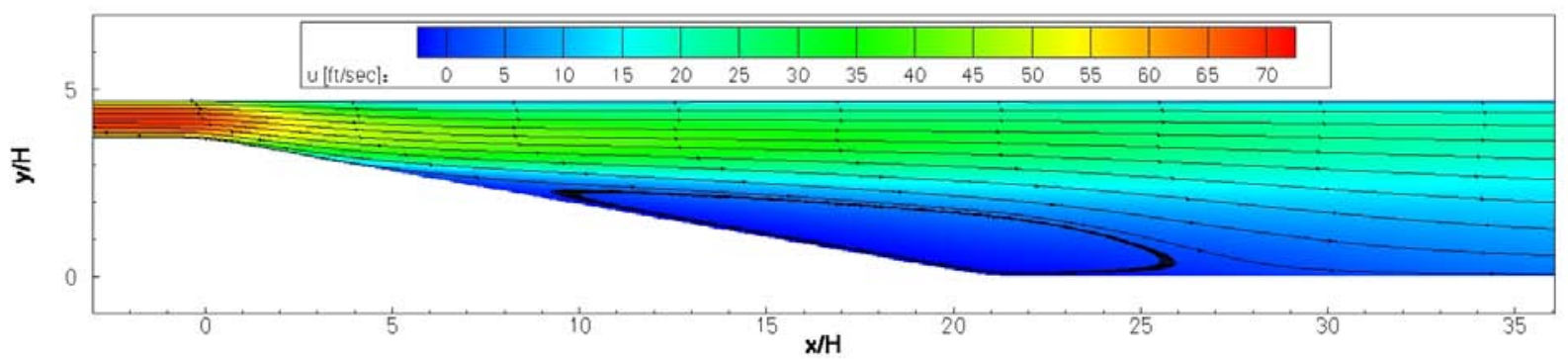

(a) Case BE01WIS: SST model, $y^{+}=1$.

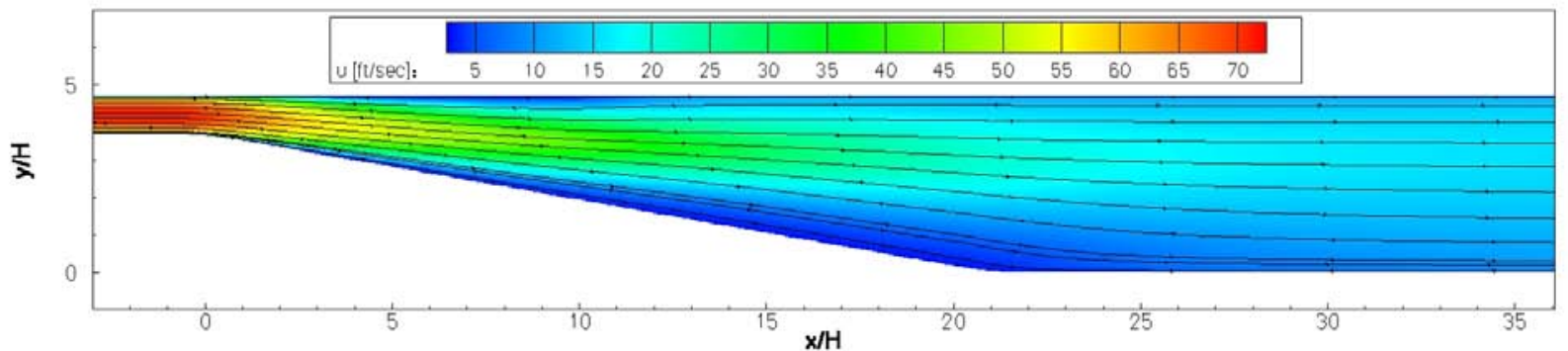

(b) Case BE01WIK: $K-\varepsilon$ model, $y^{+}=1$.

Figure 13: Velocity contour plot Buice-Eaton diffuser.

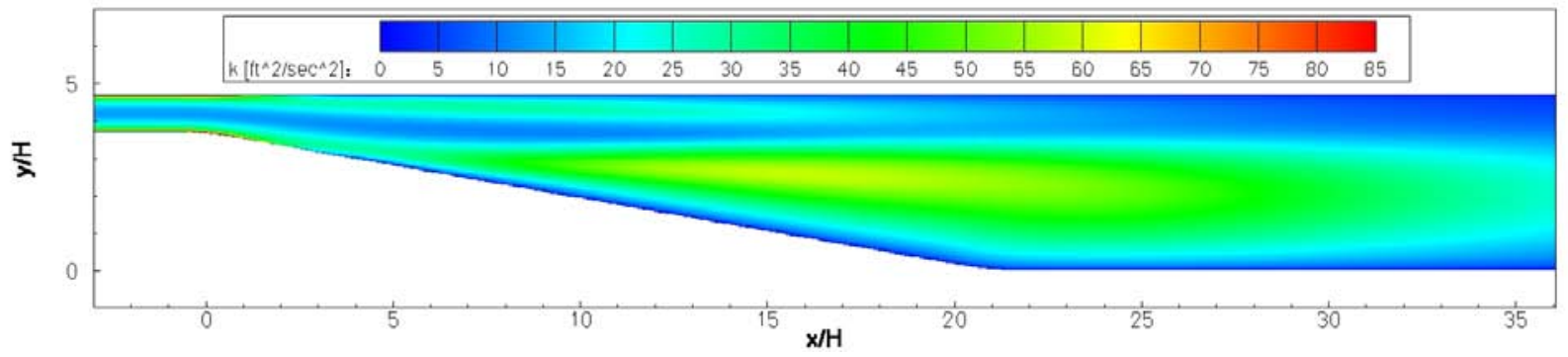

(a) Case BE01WIS: SST model, $y^{+}=1$.

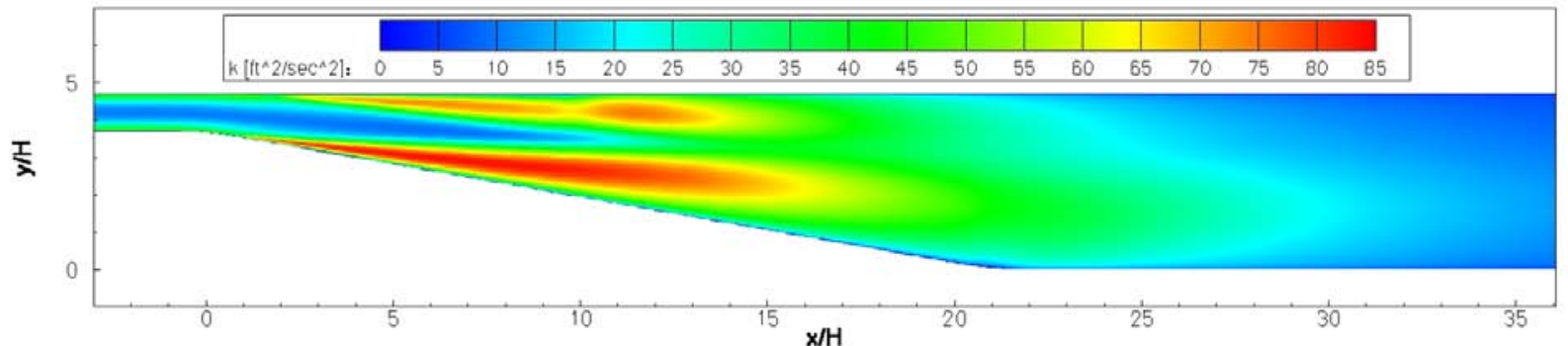

(b) Case BE01WIK: $K-\varepsilon$ model, $y^{+}=1$.

Figure 14: TKE contour plot Buice-Eaton diffuser. 


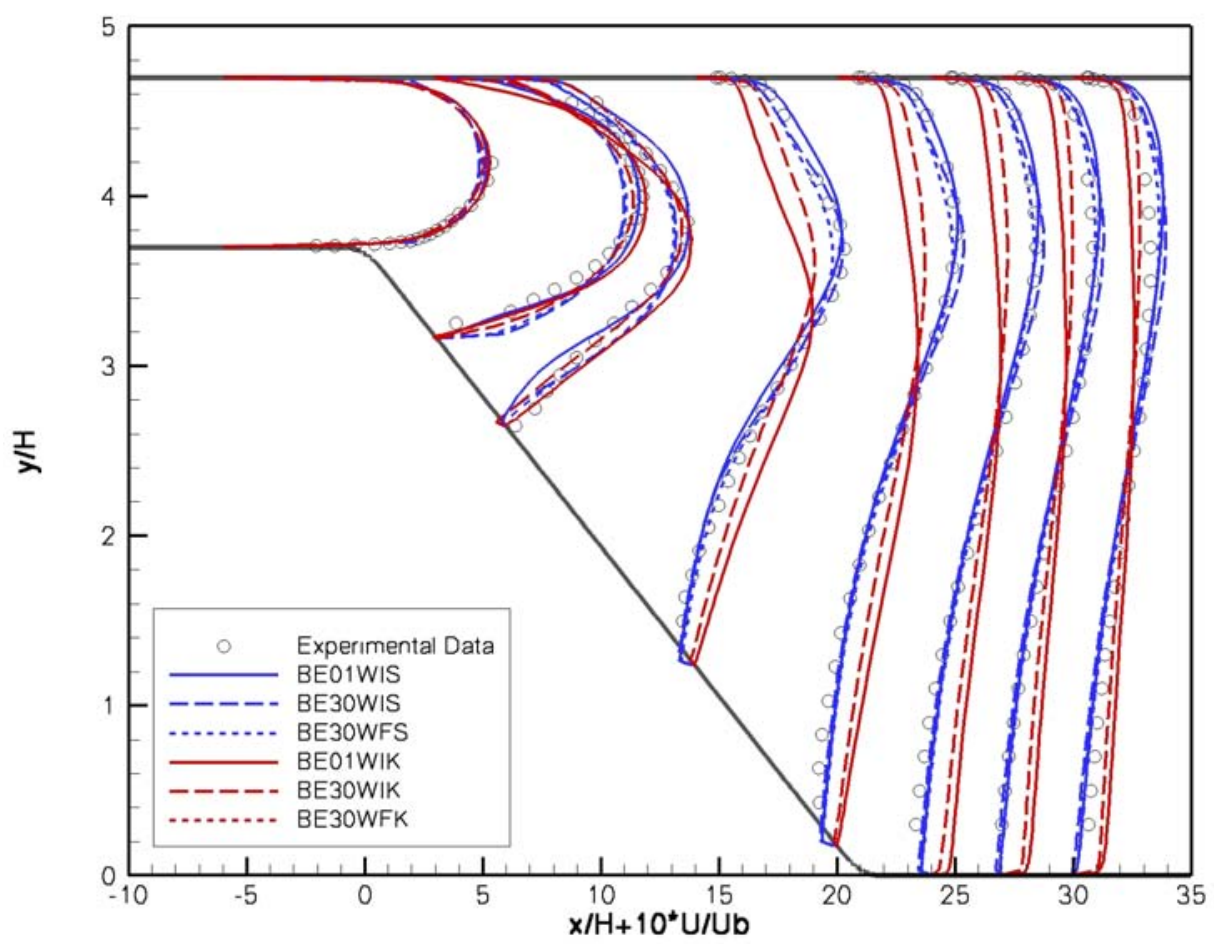

Figure 15: Velocity profiles in Buice-Eaton diffuser. Comparison of turbulence models.

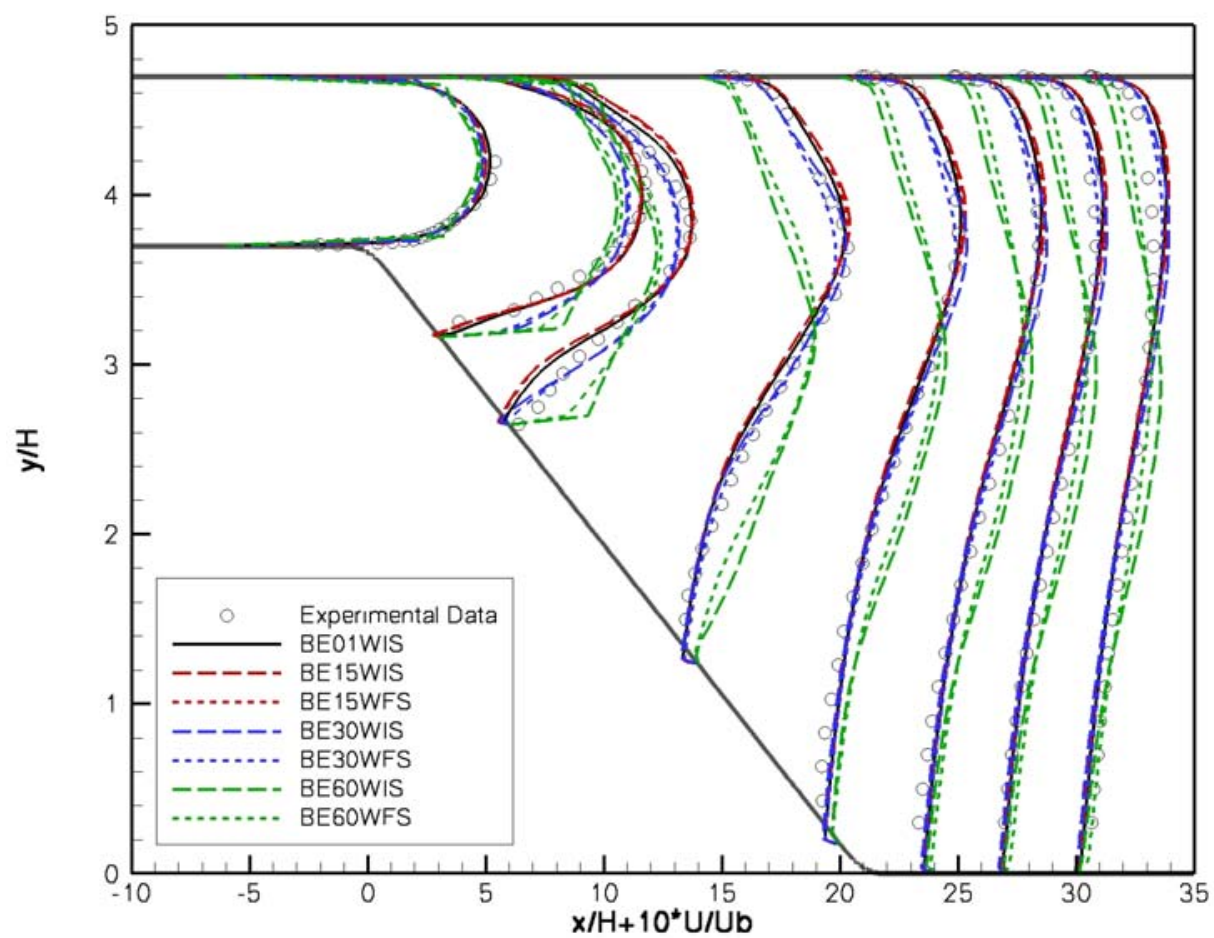

Figure 16: Velocity profiles in Buice-Eaton diffuser. Comparison of wall function/wall integration. 


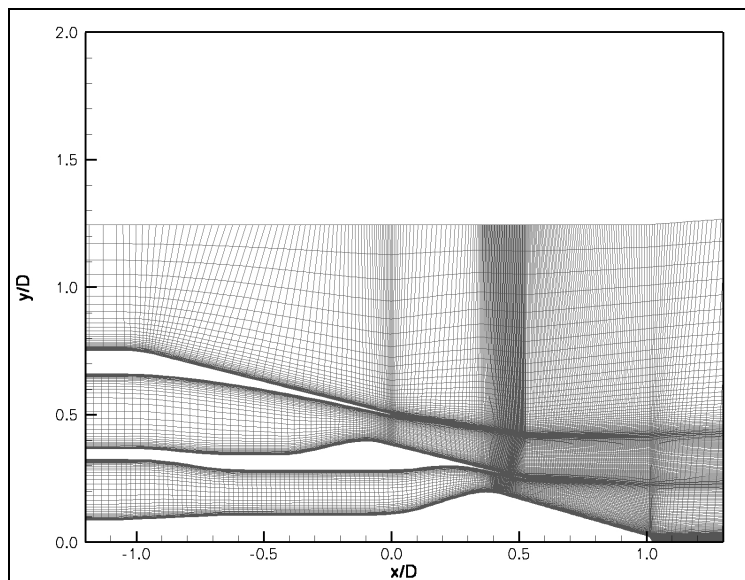

(a) Entire nozzle

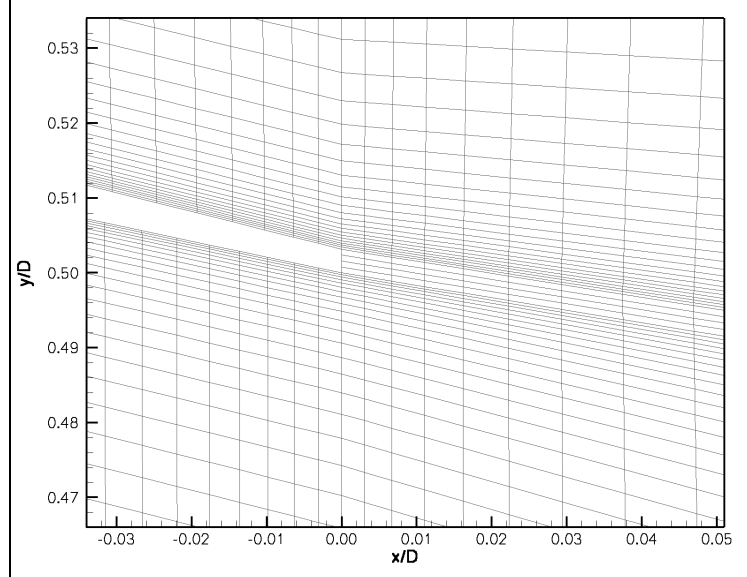

(b) Detail of nozzle near secondary flow exit

Figure 17: Wall function grid. (Note loosely packed cells at wall.)

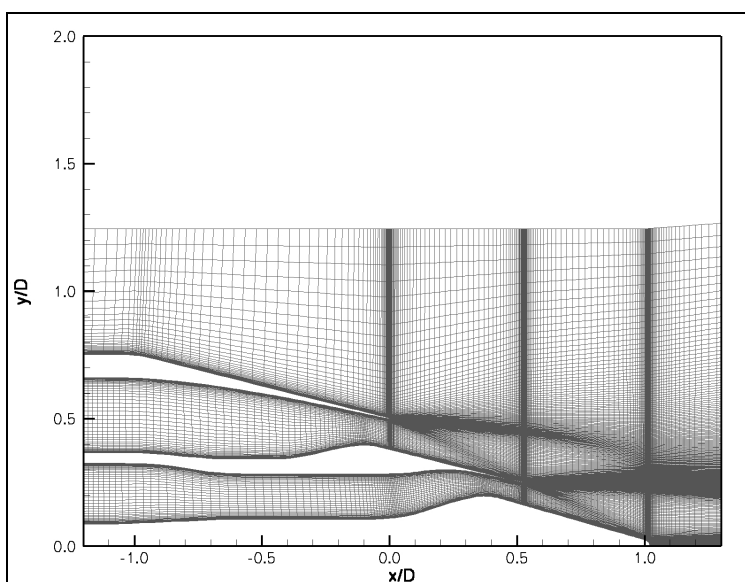

(a) Entire nozzle

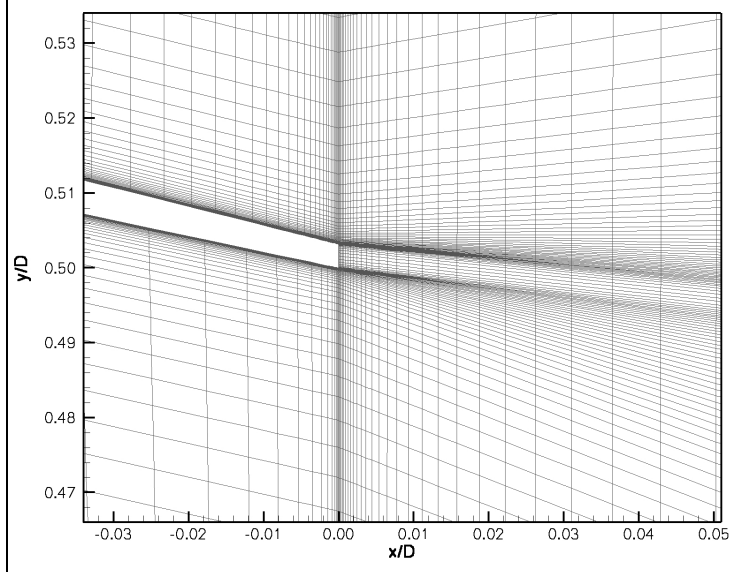

(b) Detail of nozzle near secondary flow exit

Figure 18: Wall integration grid. (Note tightly packed cells at walls.) 


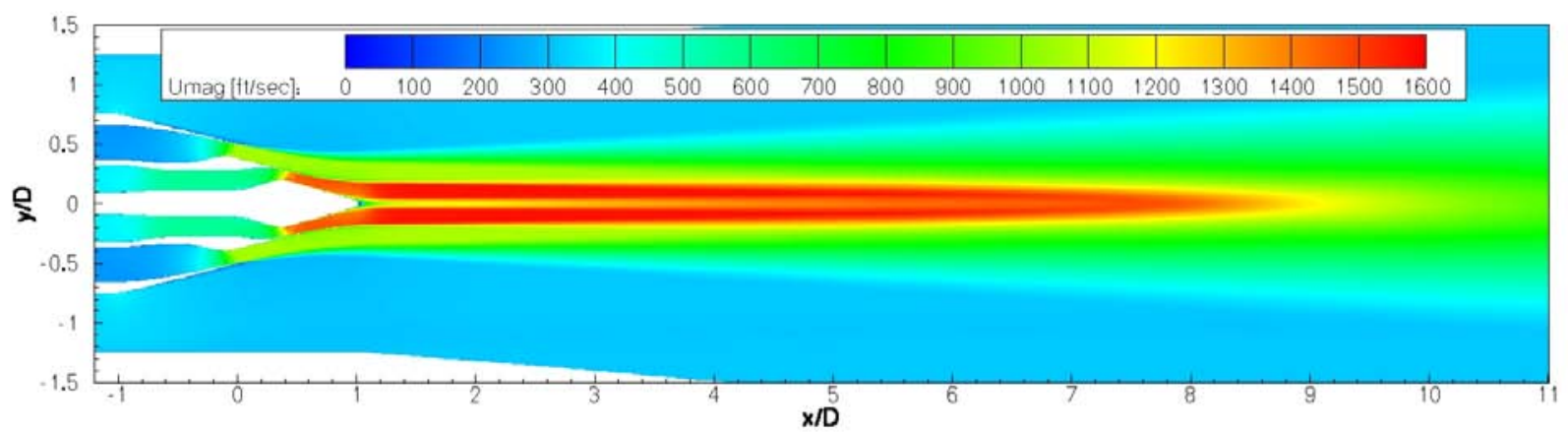

(a) Velocity contours

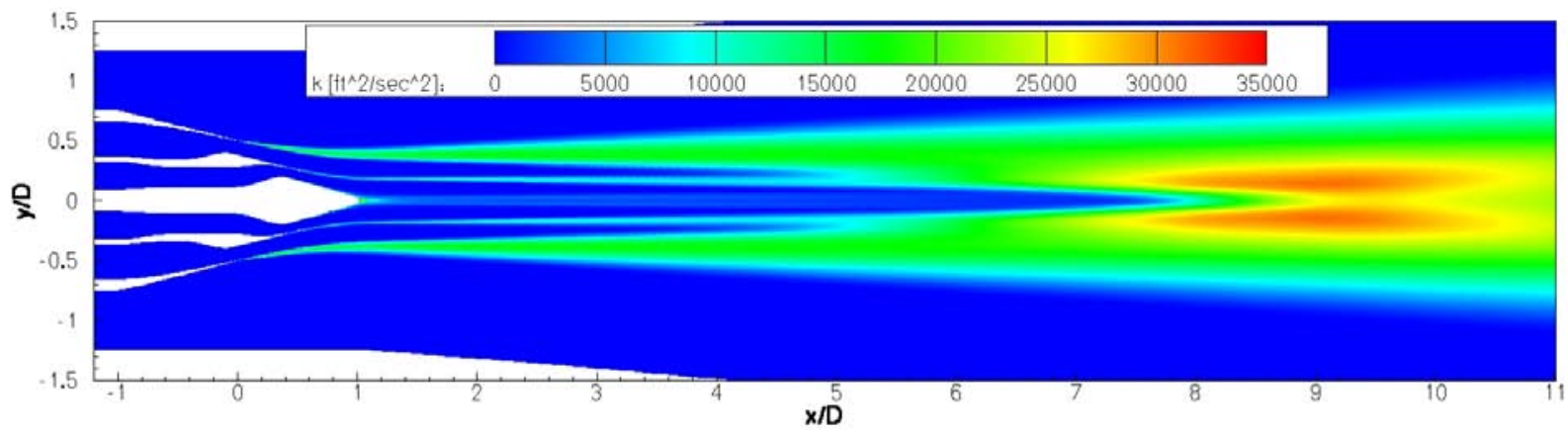

(b) TKE contours

Figure 19: Flowfield contour plots of 3BB nozzle. Case 3BB01WIK $\mu$ shown.

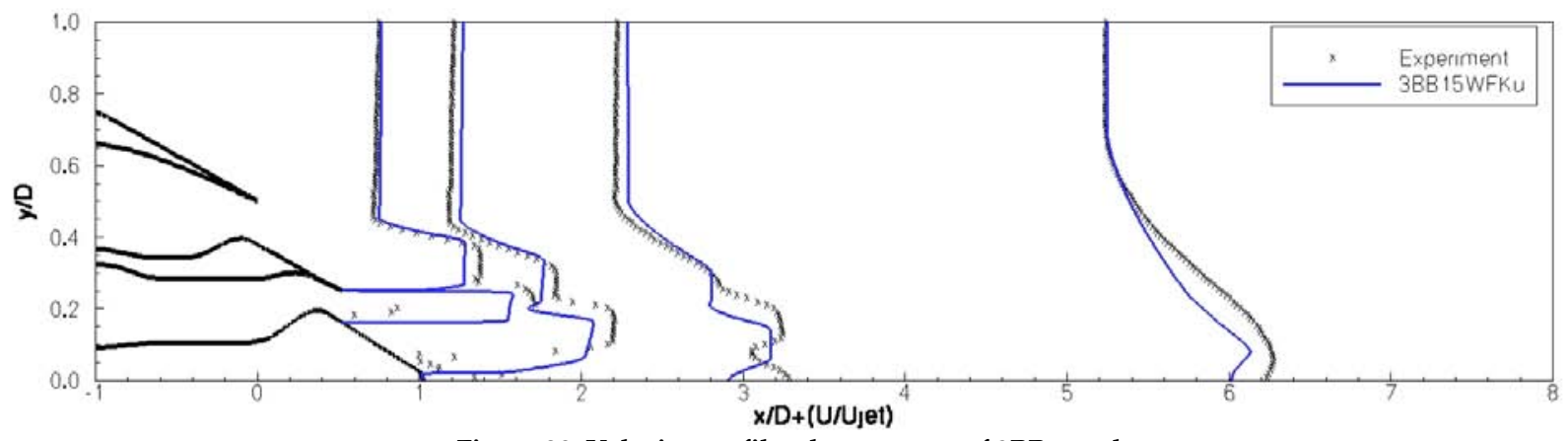

Figure 20: Velocity profiles downstream of $3 \mathrm{BB}$ nozzle.

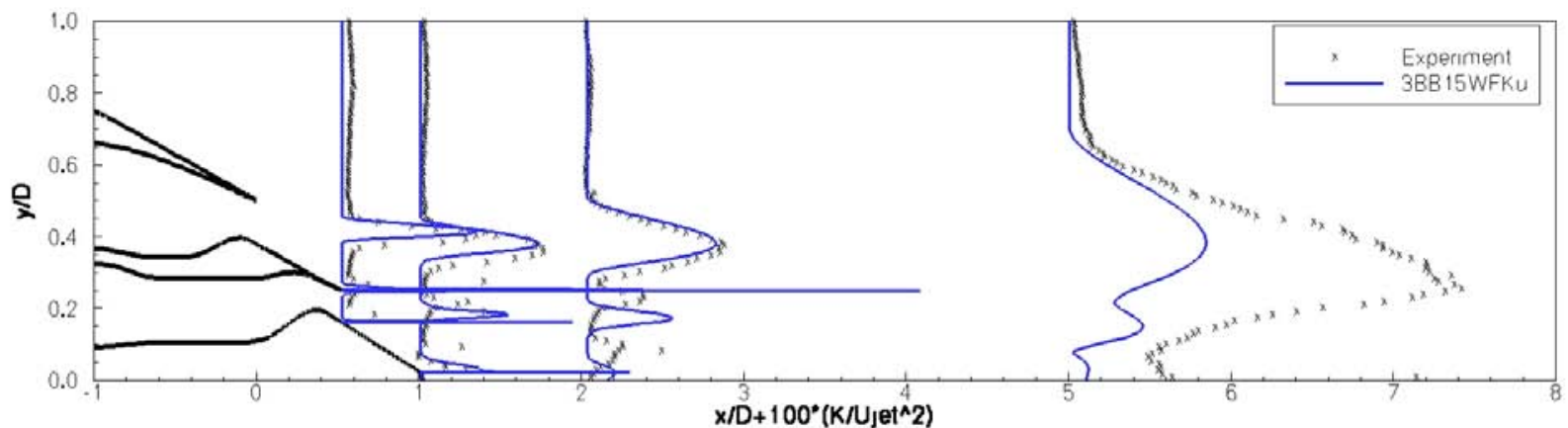

Figure 21: TKE profiles downstream of 3BB nozzle. 


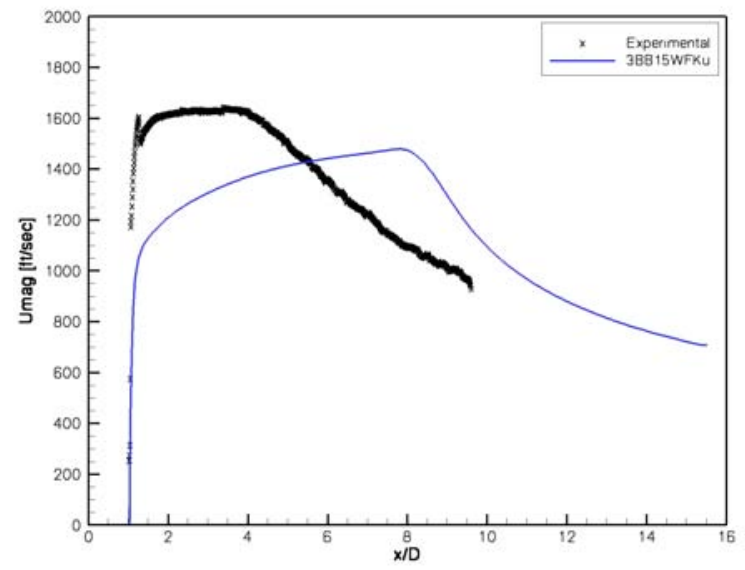

Figure 22: Centerline velocity magnitude of 3BB nozzle.

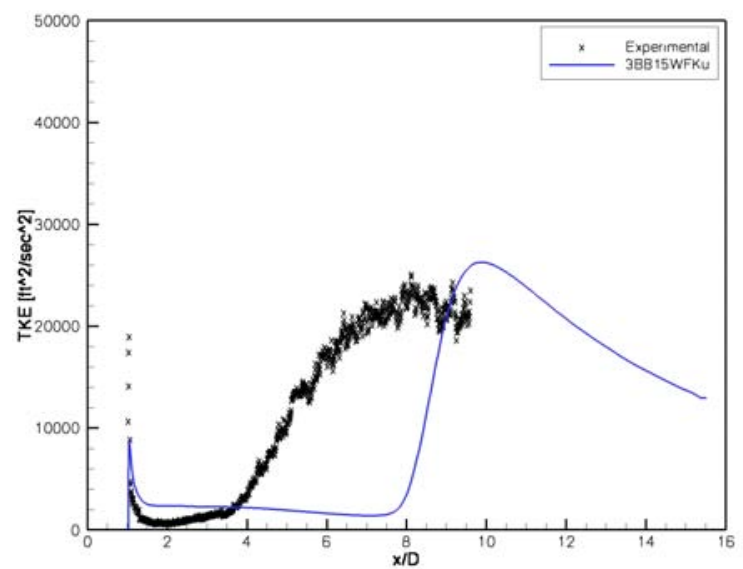

(a) Centerline TKE

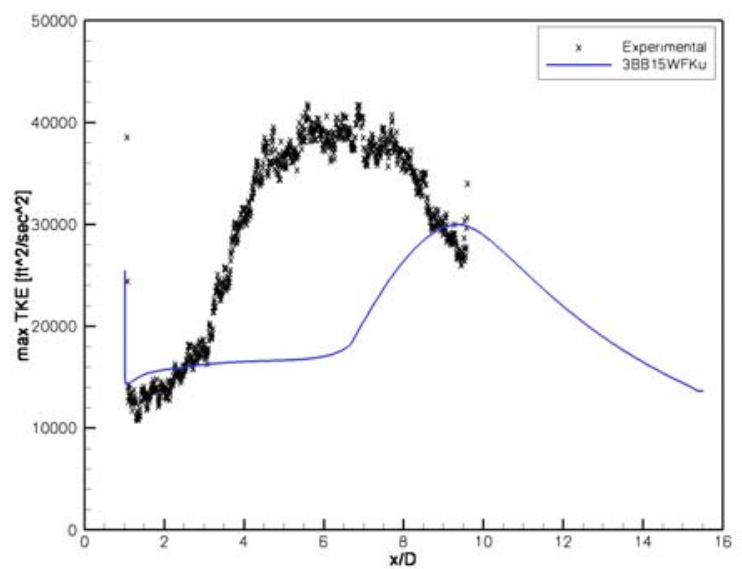

(b) Maximum TKE

Figure 23: TKE downstream of the 3BB nozzle. 


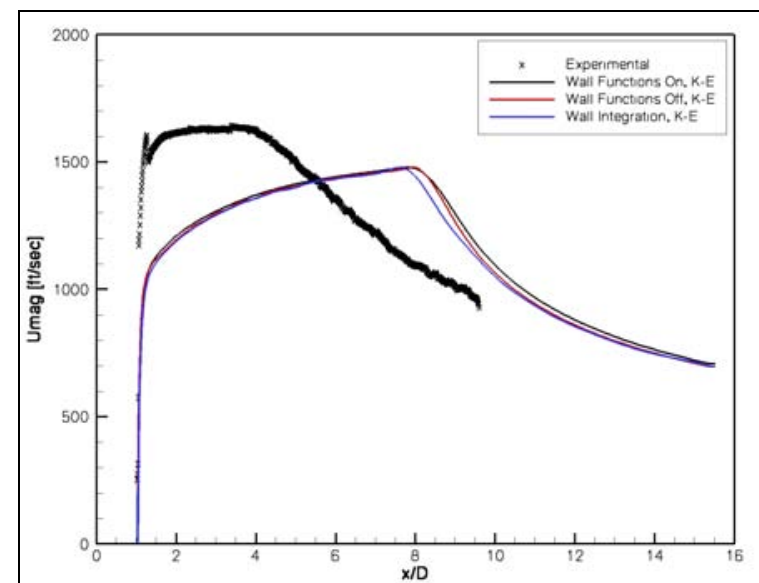

(a) Centerline velocity magnitude

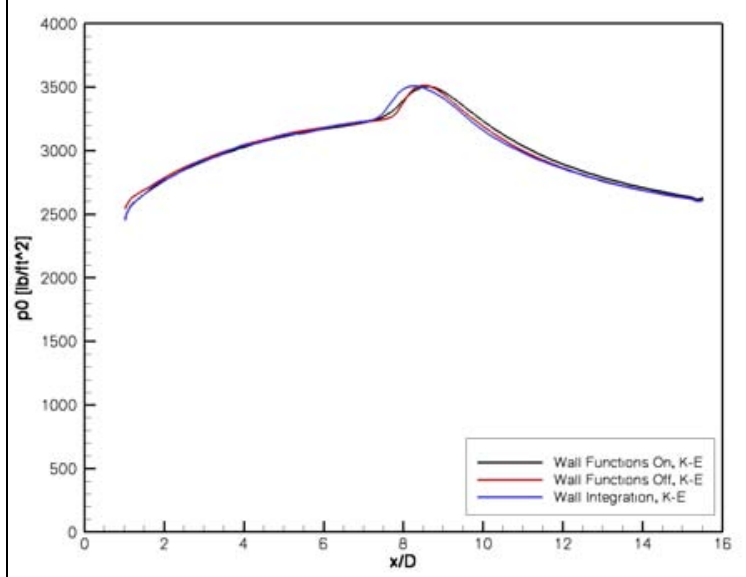

(b) Centerline total pressure

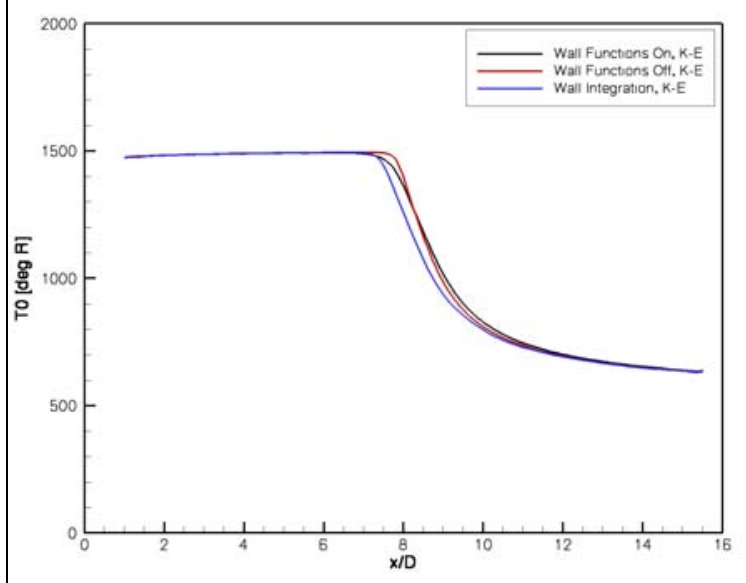

(c) Centerline total temperature

Figure 24: Studies with baseline grid topology with $K-\varepsilon$ turbulence model (Cases 3BB15WFK, 3BB15WIK, 3BB01WIK).

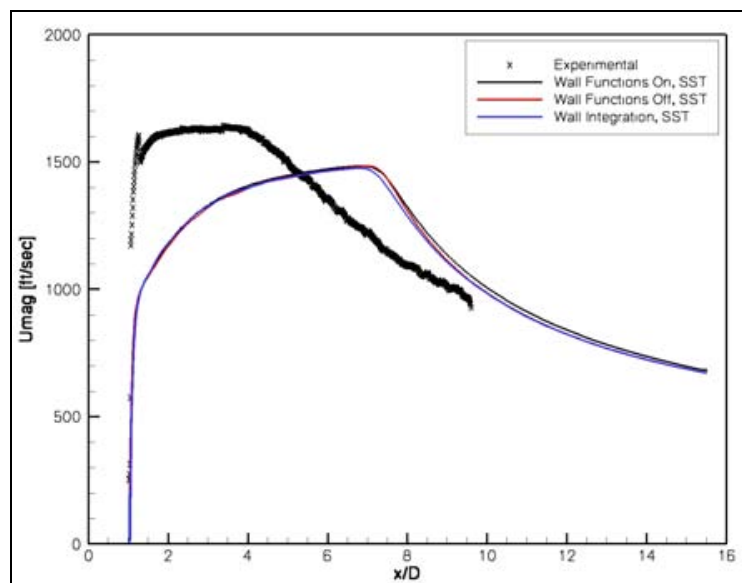

(a) Centerline velocity magnitude

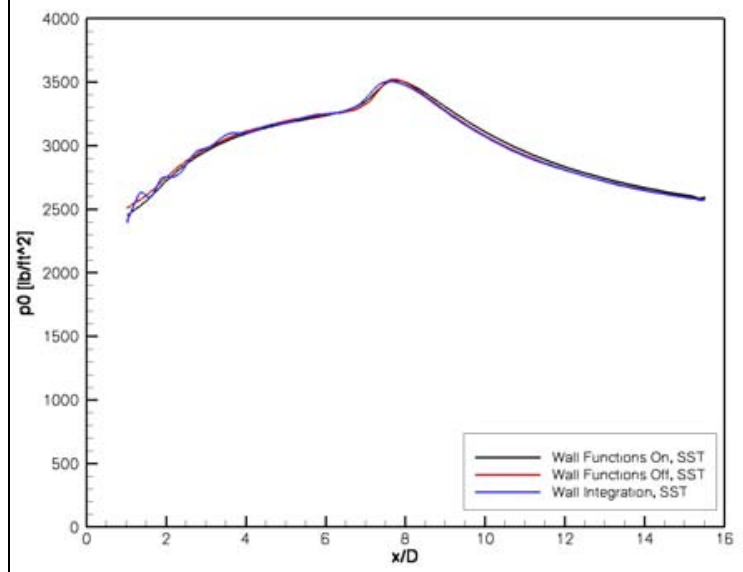

(b) Centerline total pressure

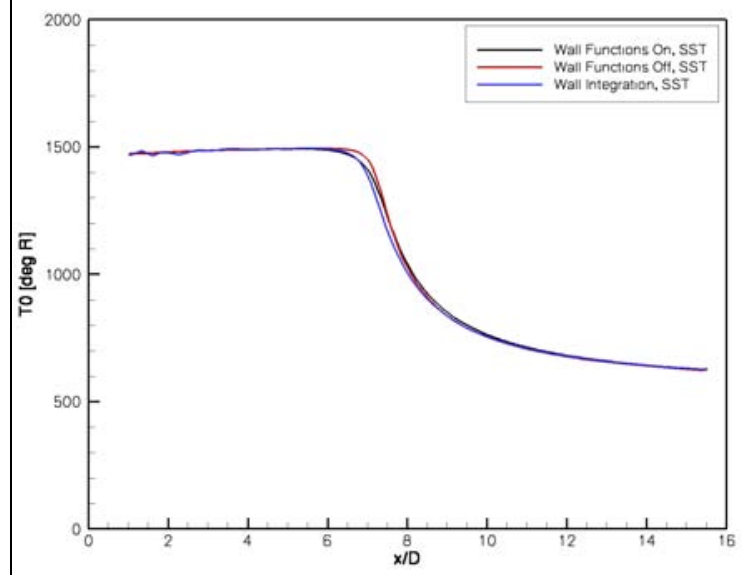

(c) Centerline total temperature

Figure 25: Studies with baseline grid topology with SST turbulence model (Cases 3BB15WFS, 3BB15WIS, 3BB01WIS). 


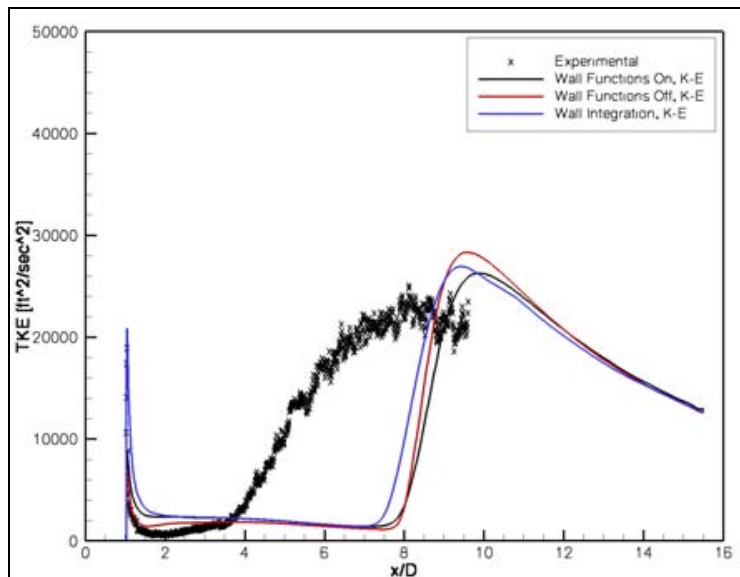

(a) Centerline TKE

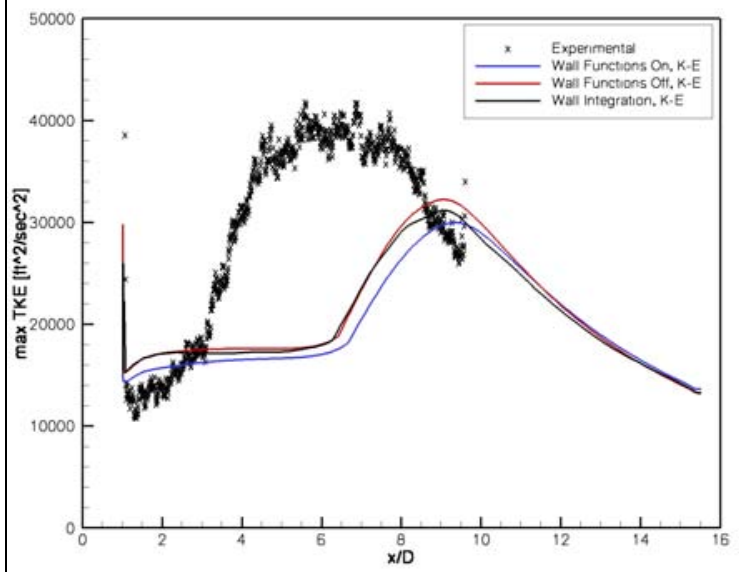

(b) Maximum TKE

Figure 26: Studies with baseline grid topology with $K-\varepsilon$ turbulence model (Cases 3BB15WFK, 3BB15WIK, 3BB01WIK).

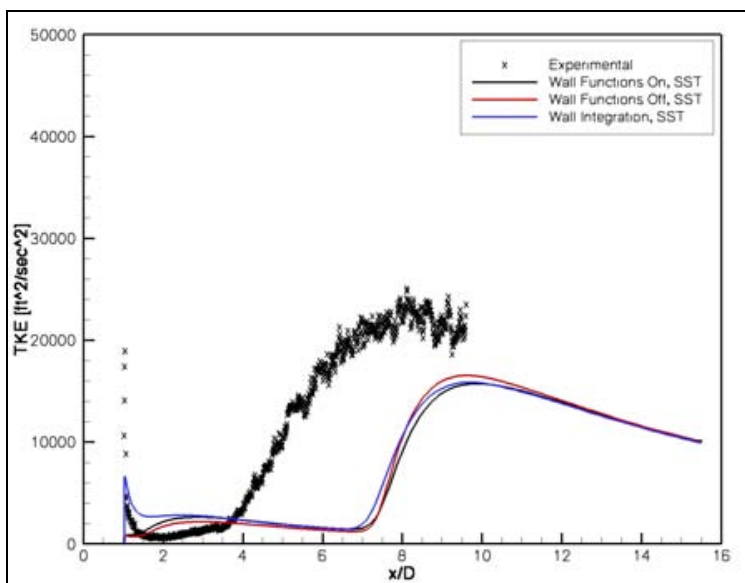

(a) Centerline TKE

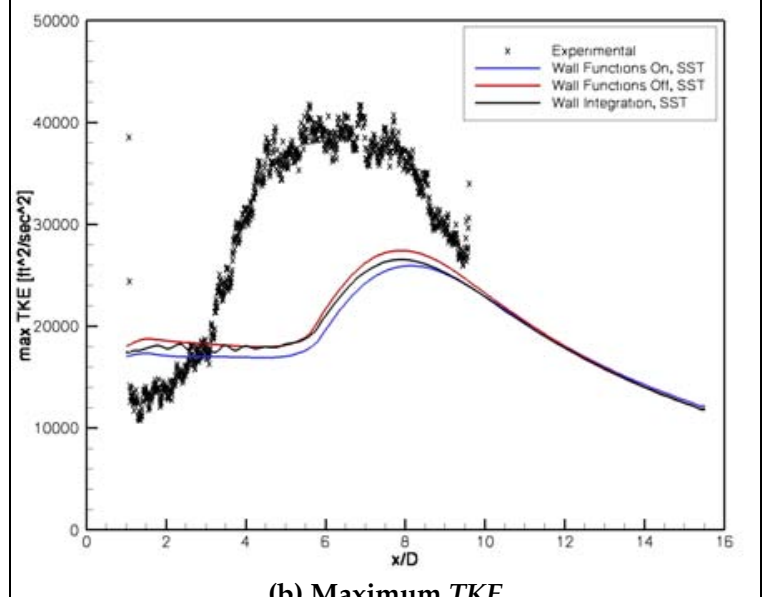

(b) Maximum TKE

Figure 27: Studies with baseline grid topology with SST turbulence model (Cases 3BB15WFS, 3BB15WIS, 3BB01WIS). 


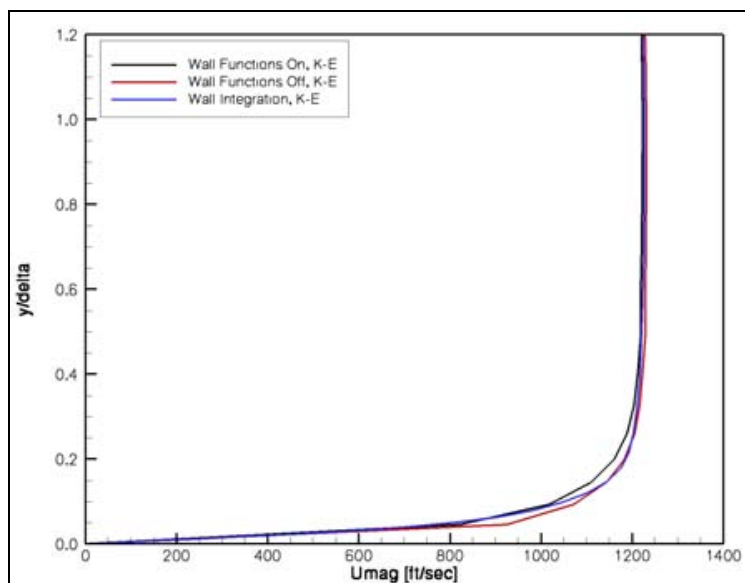

(a) Primary nozzle boundary layer velocity profile

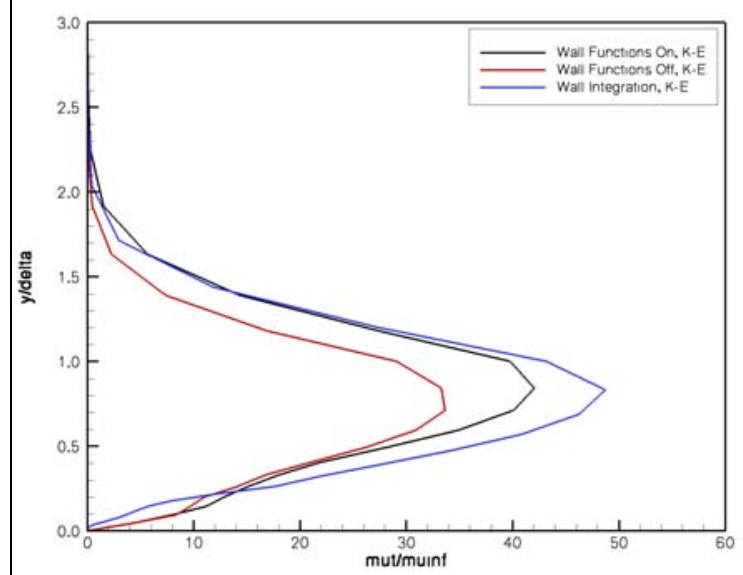

(b) Primary nozzle boundary layer turbulent viscosity profile

Figure 28: Studies with baseline grid topology with $K-\varepsilon$ turbulence model (Cases 3BB15WFK, 3BB15WIK,

3BB01WIK).

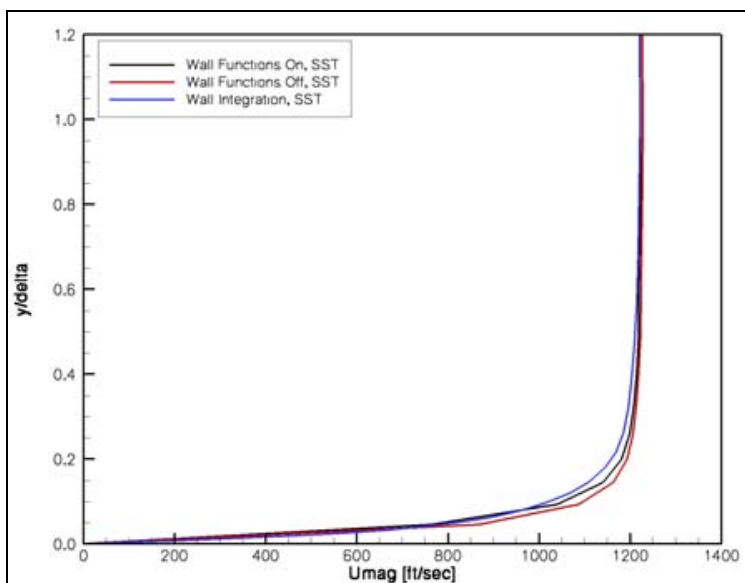

(a) Primary nozzle boundary layer velocity profile

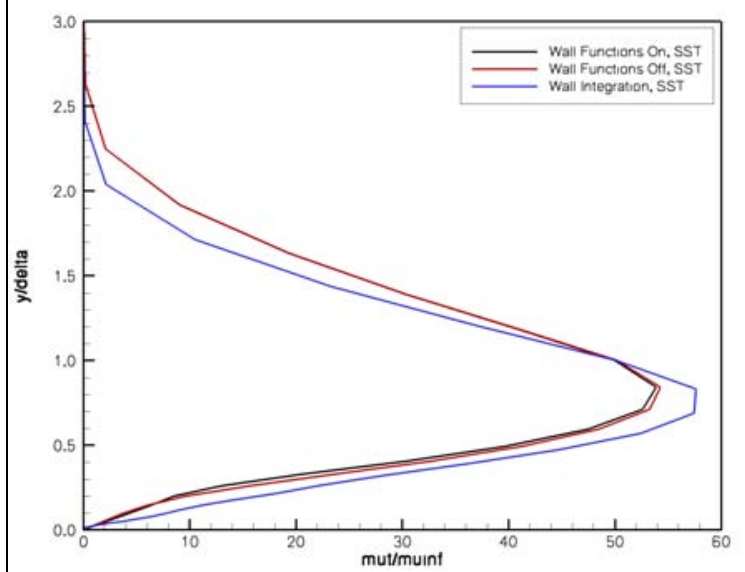

(b) Primary nozzle boundary layer turbulent viscosity profile

Figure 29: Studies with baseline grid topology with SST turbulence model (Cases 3BB15WFS, 3BB15WIS,

3BB01WIS). 


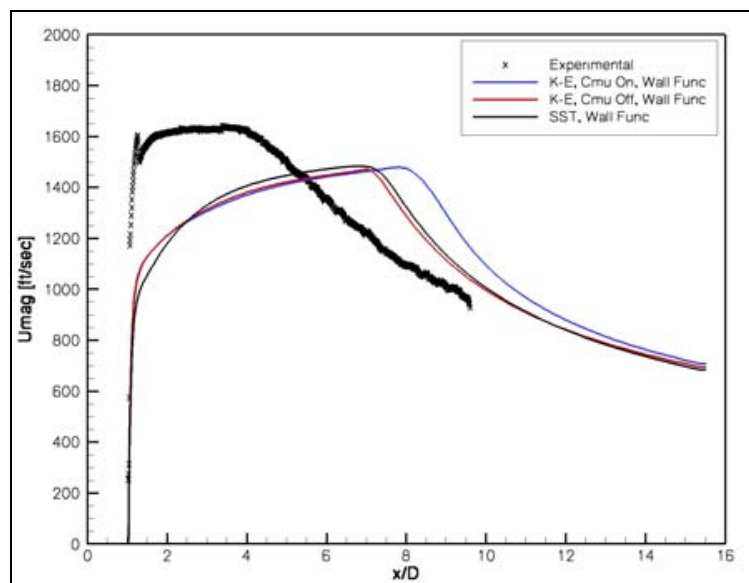

(a) Centerline velocity magnitude

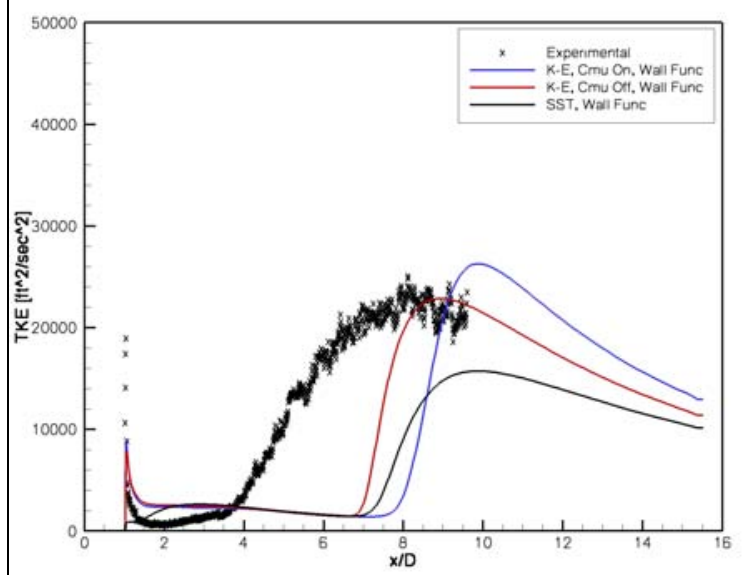

(b) Centerline TKE

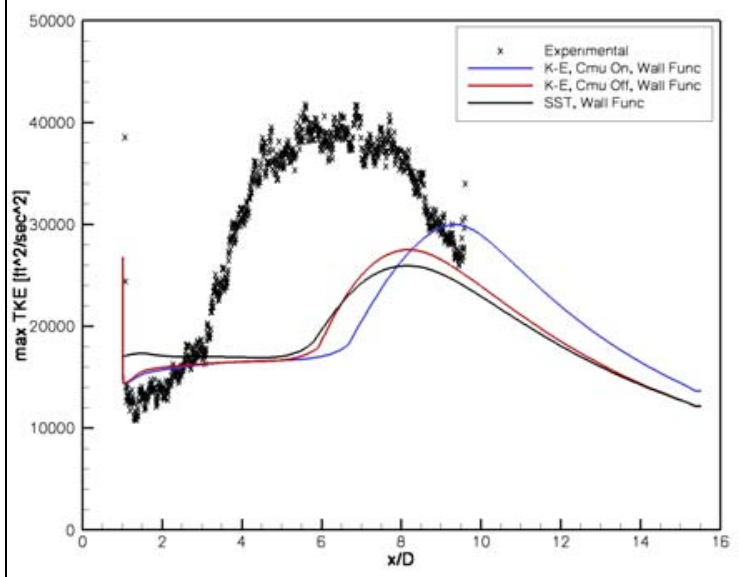

(c) Maximum TKE

Figure 30: Turbulence model comparison with wall functions (Cases 3BB15WFK $\mu$, 3BB15WFK, and 3BB15WFS).

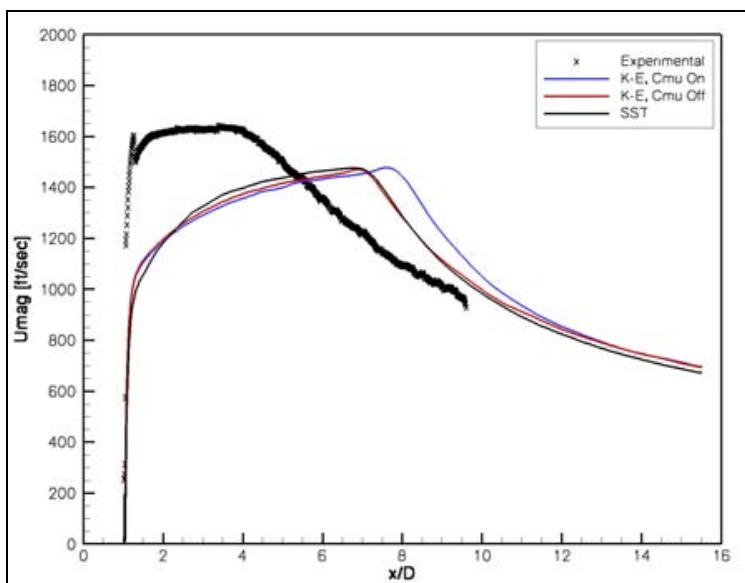

(a) Centerline velocity magnitude

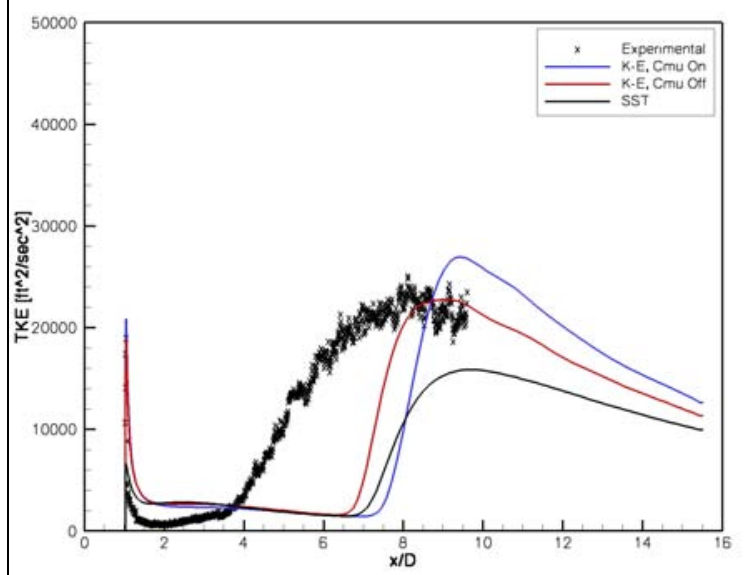

(b) Centerline TKE

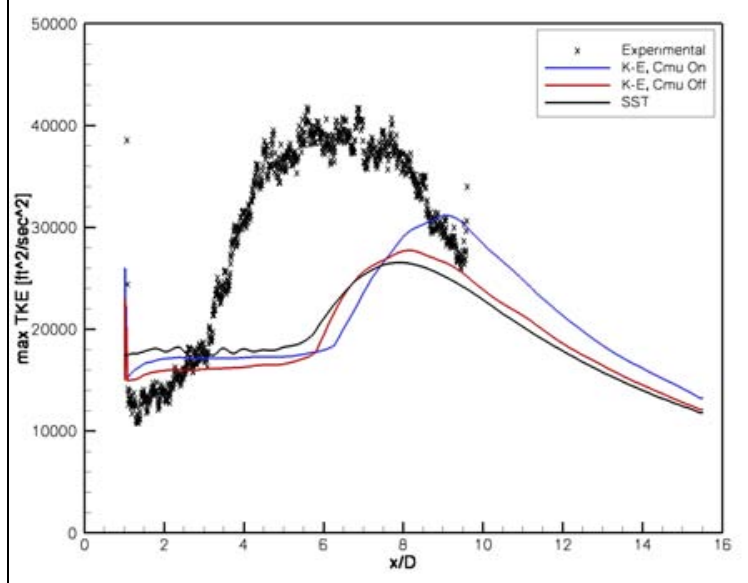

(c) Maximum TKE

Figure 31: Turbulence model comparison with wall integration Cases 3BB01WFK $\mu, 3 B B 01 W F K$, and 3BB01WFS. 


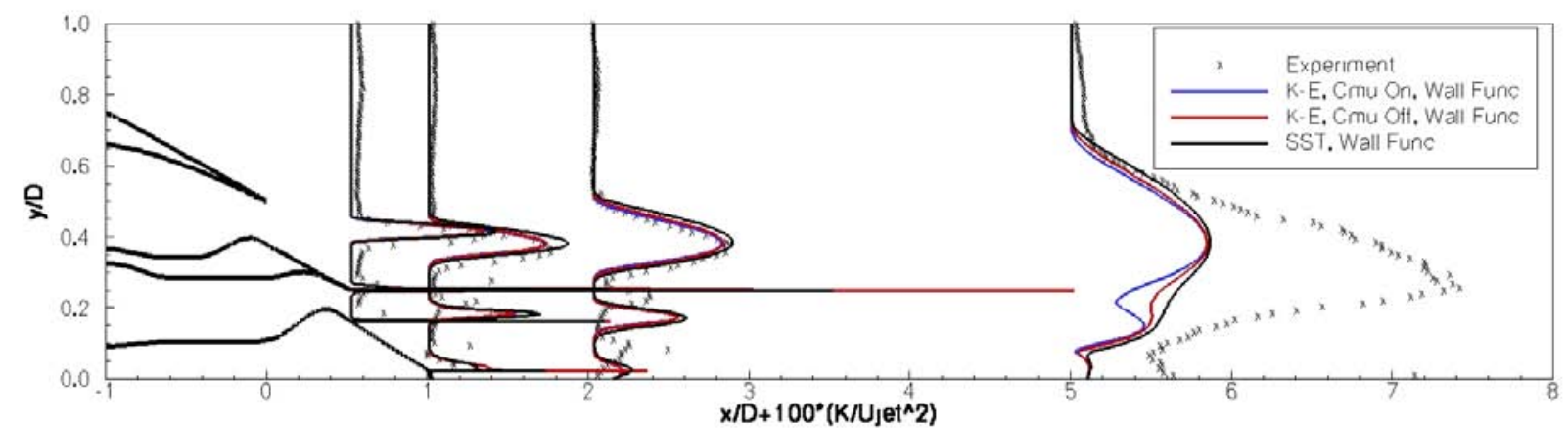

(a) Turbulence model comparison with wall functions (Cases 3BB15WFK $\mu$, 3BB15WFK, and 3BB15WFS).

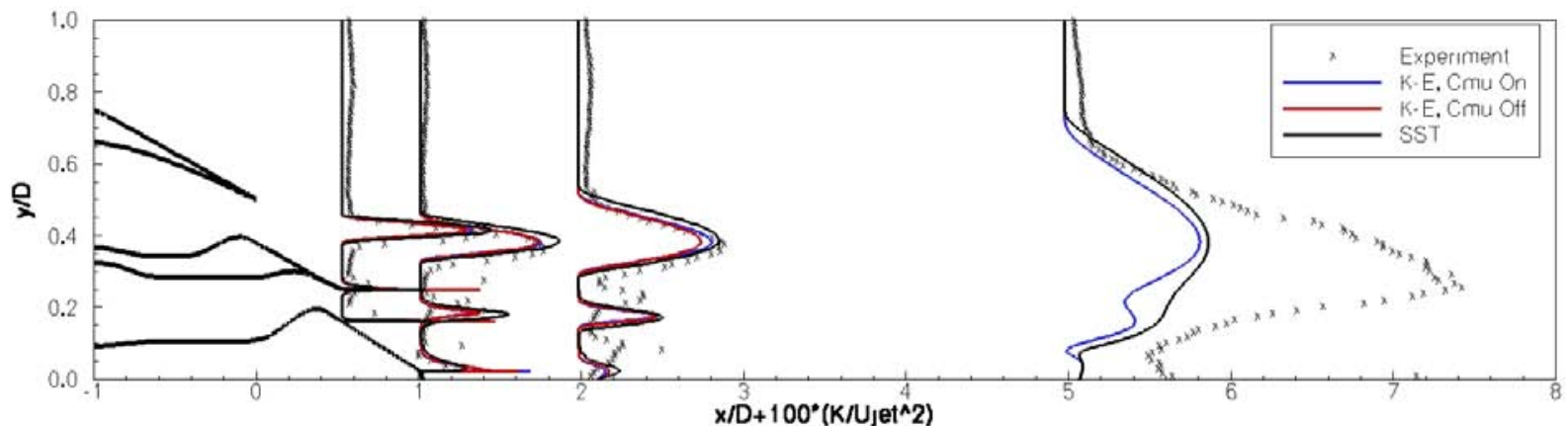

(b) Turbulence model comparison with wall integration (Cases 3BB01WFK $\mu$, 3BB01WFK, and 3BB01WFS).

Figure 32: TKE profiles downstream of 3BB nozzle. 